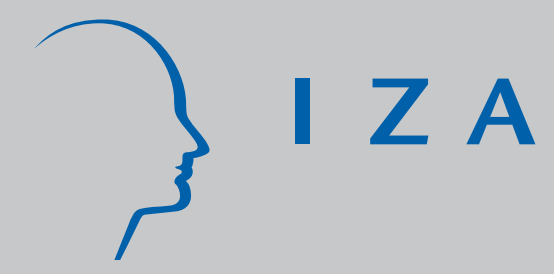

IZADP No. 1642

U.S. Border Enforcement and the Net Flow of Mexican Illegal Migration

Manuela Angelucci

J une 2005 


\title{
U.S. Border Enforcement and the Net Flow of Mexican Illegal Migration
}

\author{
Manuela Angelucci \\ University of Arizona \\ and IZA Bonn
}

\author{
Discussion Paper No. 1642 \\ June 2005
}

IZA

P.O. Box 7240

53072 Bonn

Germany

Phone: +49-228-3894-0

Fax: +49-228-3894-180

Email: iza@iza.org

\begin{abstract}
Any opinions expressed here are those of the author(s) and not those of the institute. Research disseminated by IZA may include views on policy, but the institute itself takes no institutional policy positions.

The Institute for the Study of Labor (IZA) in Bonn is a local and virtual international research center and a place of communication between science, politics and business. IZA is an independent nonprofit company supported by Deutsche Post World Net. The center is associated with the University of Bonn and offers a stimulating research environment through its research networks, research support, and visitors and doctoral programs. IZA engages in (i) original and internationally competitive research in all fields of labor economics, (ii) development of policy concepts, and (iii) dissemination of research results and concepts to the interested public.
\end{abstract}

IZA Discussion Papers often represent preliminary work and are circulated to encourage discussion. Citation of such a paper should account for its provisional character. A revised version may be available directly from the author. 


\section{ABSTRACT \\ U.S. Border Enforcement and the Net Flow of Mexican Illegal Migration*}

This paper investigates the effect of U.S. border enforcement on the net flow of Mexican undocumented migration. It shows how this effect is theoretically ambiguous, given that increases in border controls deter prospective migrants from crossing the border illegally, but lengthen the duration of current illegal migrations. It then estimates the impact of enforcement on 1972-1993 migration net flows by merging aggregate enforcement data with micro data on potential and current illegal Mexican migrants. The econometric model accounts for the endogeneity of border controls using the Drug Enforcement Administration budget as an instrumental variable. Both the inflow and outflow of illegal Mexican migration are highly sensitive to changes in border enforcement. The estimates of the enforcement overall effect on illegal migration's net flow range across different specifications, from a decline - about $35 \%$ of the size of the effect on the inflow - to an increase. Thus, they suggest that border enforcement may not be an effective means to reduce the level of the illegal alien population in the United States.

JEL Classification: F22, J61, K42, O15

Keywords: $\quad$ illegal migration, border enforcement, Mexico

Corresponding author:

Manuela Angelucci

Department of Economics

University of Arizona

McClelland Hall 401

PO Box 210108

Tucson, AZ 85721-0108

Email: angelucm@eller.arizona.edu

\footnotetext{
* This paper is part of my doctoral dissertation. I am grateful to Dan Ackerberg, Gian Luigi Albano, Rabah Amir, Orazio Attanasio, Marco Cozzi, Christian Dustmann, Kei Hirano, Costas Meghir, Nicola Pavoni, Cristina Santos, Jeff Smith, and Adam Szeidl for their constructive and helpful comments. I am indebted to Gordon Hanson for providing border enforcement and apprehension data, and to the Mexican Migration Project team for making their data publicly available. All errors are mine.
} 


\section{Introduction}

This paper studies how U.S. border enforcement affects the net flow of Mexican illegal immigration. It argues that tight border controls may have perverse effects on the net flow of illegal migration because they influence the behavior of both prospective and current migrants: while enforcement increases may deter prospective migrants from crossing the border illegally, the higher migration costs may increase current migrants' length of stay in the United States. This second effect is potentially important, given the large size and the high mobility of undocumented Mexican migrants. ${ }^{1}$ If tougher border enforcement lengthens migration duration, patrol of the border might, to some extent, indirectly encourage the formation of a more permanent undocumented resident community.

Border enforcement has been a cornerstone of U.S. immigration policy, particularly since the second half of the 1980s. Understanding the impact of border controls on the flow of illegal Mexican migration is of primary importance for several reasons. First, Mexican nationals account for 69 percent of the total unauthorized resident population of the United States. Second, most illegal Mexican entries occur through the southern U.S. border. Third, undocumented Mexican migrants tend to be very mobile, undertaking multiple U.S. trips over their life cycle. Donato et al. (1992), for instance, show that migrating at least once increases the likelihood of undertaking future migrations.

The undocumented resident population of Mexican nationality has grown from 1.1 million in 1980 to 2 million in 1990 and 4.8 million in 2000 (INS Statistical Yearbooks), with an average annual growth of 90,000 in the 1980 s and 280,000 in the 1990s. At the same time, the intensity of border enforcement has nearly tripled between the early 1970s and the mid 1990s. The allocated resources to border patrol have been growing steadily, especially since the 1986 Immigration Reform and Control Act. The large growth in undocumented migration despite higher expenditures on border controls calls into question the effectiveness of such policy.

The fact that border enforcement affects illegal migrants' outflow, as well as inflow, may provide an additional explanation for the disproportionate resources allocated to border versus interior enforcement. If the effectiveness of border patrol is measured by its reduction in undocumented entries only, neglecting its impact on migrant outflow, the resulting estimate will overstate border enforcement's true effect on migration net flow. This may cause a larger than optimal resource allocation to border controls. Although there is awareness of these issues both at the theoretical and anecdotal level, the existing literature has focused almost entirely on border enforcement's impact on migration inflow only, not considering its effect on the outflow of illegal migrants.

\footnotetext{
${ }^{1}$ Massey and Singer (1995) provide estimates of annual inflow and outflow of U.S.-based Mexican migrants.
} 
This paper contributes to the existing literature in several ways. First, it shows how the impact of border patrol on migration net flow is theoretically ambiguous. To do so, it presents a simple model where agents may prefer to undertake multiple, costly migrations over a single longer one. The previous literature has explained multiple migrations as the consequence of shocks or of imperfect information. I show that if absence from home entails a positive disutility that increases more than proportionally in time spent away from home, repeated, short-term migrations may maximize inter-temporal utility even with complete information and with a fixed cost per migration. This setting enables me to endogenize migration duration.

Second, this paper provides, for the first time, direct estimates of the effect of border enforcement on the net flow of undocumented Mexican migrants. For this purpose, I merge aggregate border enforcement with individual-level data on undocumented migration from the Mexican Migration Project. Thus, I can observe how border controls affect the likelihood of both undertaking and returning from an illegal migration. The obtained estimates are consistent with the model predictions. Border enforcement has a significant deterrent effect, i.e. it reduces illegal migration inflow, discouraging prospective migrants from attempting an illegal trip to the United States. At the same time, it lengthens the U.S. permanence of current migrants. Between 1972 and 1993, the estimated enforcement elasticity of inflows is -0.65 to -1.53 at the mean, depending on the specification and sample used, while the elasticity of outflows varies between -0.73 and -1.56 . The effect of a marginal increase in enforcement on illegal migration net flow varies between $35 \%$ of its impact on the inflow to an overall increase. These empirical results confirm the model's prediction that assessing the effectiveness of border enforcement by analyzing its deterrent effect provides an overestimate of its true impact; they further suggest that border enforcement may not be an adequate policy to limit the illegal migrant net flow. The final contribution of this paper is to propose a new instrument, the Drug Enforcement Administration budget, to address the issue of the endogeneity of border controls in the econometric specification.

The paper is organized as follows. Section 2 reviews the existing literature. Section 3 derives testable hypotheses of the impact of border enforcement on both the inflow and outflow of undocumented migrants using a dynamic model of illegal migration with heterogenous costs. Section 4 describes the data used. Section 5 discusses how the sample design may bias the estimates of the border controls coefficient and provides estimates of the aggregate illegal migration inflow. Section 6 illustrates the empirical specification and the related estimation and identification issues. Section 7 presents the results from the econometric analysis, estimates the marginal effect of enforcement on the undocumented Mexican migrant net flow, highlighting some policy implications. Section 8 concludes. 


\section{Literature review}

There is a growing literature trying to understand the relationship between illegal migration and border enforcement. The main practical problem faced by this literature is the difficulty of directly measuring the stock and flow of illegal migration. ${ }^{2}$ This literature focuses in particular on the relationship between enforcement and illegal migrant inflow. Several papers use records of aggregate apprehension of illegal border crossers to infer the effect of enforcement on the undocumented migrant inflow. Borjas et al. (1991) look at the relation between apprehensions and expenditure for border enforcement. Bean et al. (1990) assess the impact of the 1986 Immigration Reform and Control Act. Espenshade (1994) tests the deterrent effect of the likelihood of border apprehension on the inflow of undocumented migration. Hanson and Spilimbergo (1999), estimate the elasticity of apprehensions with respect to border enforcement from a reduced-form aggregate apprehension function. Davila et al. (2001) estimate the short and long-run deterrent effect of border controls. ${ }^{3}$

However, if one wants to estimate how border enforcement affects the stock of illegal migrants, the variable of interest is migration net flow: the effect of border controls on migration inflow is likely to differ from its impact on the net flow, if enforcement also changes illegal migrants' outflow. The fact that tighter enforcement, which causes an increase in migration costs, affects both the likelihood and the duration of an undocumented migration is illustrated in Hill (1987). His model shows that higher enforcement may reduce the number of migrations while increasing their length. More recently, Cornelius (2001) mentions the possibility that higher migration costs may result in lower mobility for undocumented individuals, once they have reached the destination country. The same point is made in a survey by The Economist (2002).

Kossoudji (1992) uses a sample of repeated illegal Mexican migrants to estimate the effect of past apprehension on current migration frequency and duration. This is the only previous empirical paper I am aware of where apprehension is related to migration duration. Unfortunately, the data set Kossoudji uses does not permit to distinguish interior from border apprehensions.

\footnotetext{
${ }^{2}$ Warren and Passel (1987) use U.S. Census data to estimate the stock of undocumented aliens. Massey and Singer (1995) obtain estimates of individual probability of apprehension to assess the magnitude of the net flow of illegal migration.

${ }^{3}$ However, only tentative inference can be made to estimate from apprehension data by how much border patrol reduces the illegal migration inflow: under current U.S. immigration law, the same individual may be arrested several times while trying to cross the border. If an apprehended illegal alien agrees on a voluntary departure, that person is simply transported back to the Mexican side of the border. Thus number of arrests does not clearly represent the volume of apprehended migrants. Espenshade (1995b) estimates the relationship between aggregate attempts and apprehensions using a repeated trials model of illegal migration and presents a way of obtaining estimates of the flow of undocumented aliens by observing the fraction of repeated apprehensions of the same individuals. However, collection of this piece of information has been discontinued since the late 1980s.
} 
Furthermore, being a sample of migrants only, one cannot estimate the effect of enforcement on migration inflow (i.e. the number of individuals discouraged from attempting to migrate by the high level of border controls). This paper adds to the existing literature by providing estimates of enforcement's effect on illegal migration net flow.

Another branch of the literature questions the policy effectiveness of border enforcement on different grounds from the one made above. Advocates of interior enforcement suspect that inspections to firms in undocumented labor-intensive sectors might prove more successful in the eradication of illegal migration. Work by Hanson and Spilimbergo (2001) suggests that border enforcement may be the product of conflicting interests, as controls loosen when the demand for illegal labor is high. Davila et al. (1999) argue that the disproportionate resource allocation favoring border versus interior enforcement is consistent with agency budget-maximizing behavior, rather than with trying to minimize the stock of illegal U.S. residents.

\section{$3 \quad$ A model of repeat migration}

This section models multiple migration choices of heterogeneous agents. The model is used to understand how border policing affects the decisions of starting and returning from an illegal migration, and to derive testable hypotheses and an appropriate econometric specification. In addition, it sheds light on how the survey design may bias estimates of the parameters of interest.

While we understand why people migrate and why it may be optimal to return to the home country even with a higher foreign wage (see, for instance, Borjas and Bratsberg (1996), Stark et al. (1997) and Dustmann (2003)), we know less about the determinants of repeated migration. Since moving is costly, it is not clear why individuals may prefer multiple, shorttermed migrations to a single, longer one. The literature has related multiple migrations to imperfect information or shocks (Da Vanzo (1983)). However, given the vast scale of Mexican migration to the United States and the existence of migration networks, access to information should be relatively easy and cheap. Moreover, there are other important determinants of repeated migrations over the life cycle.

Three different determinants of repeated Mexican migrations over the life cycle are: 1) labor demand cyclicality, 2) target earning behavior, and 3) migration cost increasing convexly in duration of migration. The first case explains the existence of cyclical migration patterns as the consequence of seasonal changes in labor demand. One obvious example is the increased demand for agricultural workers during harvest time, or for hotel staff during peak seasons. Target earning may arise as a consequence of failures in the financial market. Credit market imperfections prevent individuals from borrowing to undertake potentially profitable activities 
(e.g. purchases of land or machinery). Migration may be an alternative mean to raise the needed sum of money. The migrant would stay in the U.S. until he or she has saved the desired amount of money. The third case assumes that being away from home entails a migration cost that grows more than proportionally over time. For instance, the likelihood of a migrant losing claims on current and future ownership of family assets (such as land and properties) may increase convexly with time spent abroad. The longer the absence, the looser the tie with the family members left behind. The same idea applies to intangible costs, such as individuals being homesick. This hypothesis is consistent with the use of remittances as means to retain a tie with the household in the home country, or as a manifestation of altruism. The hypothesis that time away from home may be costly is also consistent with the observed evidence from the MMP71 data: the likelihood of returning from a migration is, ceteris paribus, higher for parents and married migrants, and increases with the number of children and hectares of land owned. ${ }^{4}$ The current model of repeated migration is based on the latter hypothesis, which, I believe, captures some existing features of Mexican repeat migration. In any case, there exist also alternative assumptions that yield the same implications regarding the effect of border enforcement on the intensity and duration of illegal migration, such as the seasonality or the target earning cases discussed above.

I assume that migration costs are heterogeneous. This may arise because of different reasons. Individuals may be endowed with different levels of ability to cross the border, or they may have access to private information. The data provide evidence of heterogeneity in border-crossing ability. The number of observed apprehensions for a single trip varies considerably, ranging between 0 and 15, although 78 percent of migrants manage to cross the border at first attempt, and 16 percent with up to three attempts. Alternatively, individuals may face varying degrees of financial constraints, hence financing similar trips may entail different costs. Finally, costs may vary because of distance from the border and different levels of community-specific network effects. Modeling alternative sources of heterogeneity, such as differences in labor market-related skills, would not change the sign of the impact of border controls on illegal migration inflow and outflow.

Consider a continuum of potential illegal migrants with heterogeneous migration costs deriving from different ability endowments. There are two periods in the model. Agents treat wages and border enforcement $(b p)$ as given in each period. There is no uncertainty. Assume the existence of a utility function representing individual preferences. This function depends on consumption $(c>0)$ and on the fraction of time spent in the host country $(t \in[0,1])$ and

\footnotetext{
${ }^{4}$ Note that also the target earning behavior needs to be coupled with some preference for staying in the home country, in order to explain why the individual returns from a migration despite the positive wage differential.
} 
it is assumed to be twice continuously differentiable, and additive in $c, t$, and across periods. Individuals choose the optimal migration duration in both periods given the positive wage differential between U.S. and Mexican wages $\left(w^{U S}>w^{M X}\right)$, the strictly convex disutility from staying away from home $\left(u_{t}<0 \text { and } u_{t t}<0\right)^{5}$, their appetite for consumption $\left(u_{c}>0\right.$ and $\left.u_{c c}<0\right)^{6}$, and the fixed cost associated with the illegal migration $\left(M_{C}\right)$. The latter is a positive function of border enforcement $(b p), M_{C b p}>0$, and a negative function $\left(M_{C a}<0\right)$ of an individual-specific parameter $(a \in(0,1))$ capturing heterogeneity in costs. The distribution of $a$ is continuous over its support. From now on I will refer to this parameter as ability in crossing the border. I assume capital market perfection. $r$ is the interest rate paid on savings $(S)$ and $\beta$ is the inter-temporal discount factor.

The maximization problem is:

$$
\max _{t_{1} \in[0,1], t_{2} \in[0,1], S} U\left(c_{1}, c_{2}, t_{1}, t_{2}, S ; a\right)=u\left(c_{1}\left(t_{1}, S, a\right), t_{1}\right)+\beta u\left(c_{2}\left(t_{2}, S, a\right), t_{2}\right)
$$

where

$$
\begin{aligned}
c_{1} & =t_{1} w_{1}^{U S}+\left(1-t_{1}\right) w_{1}^{M X}-M_{C}\left(b p_{1}, a\right) \mathbf{1}\left\{t_{1}>0\right\}-S \\
c_{2} & =t_{2} w_{2}^{U S}+\left(1-t_{2}\right) w_{2}^{M X}-M_{C}\left(b p_{2}, a\right) \mathbf{1}\left\{t_{2}>0 ; t_{1}<1\right\}+(1+r) S \\
w^{U S} & >w^{M X}
\end{aligned}
$$

The object $\mathbf{1}\{\}$ is an indicator function that takes the value of one when the conditions in brackets occur. ${ }^{7}$ Given the parameters of the model, different ability endowments will be associated with varying optimal migration durations, possibly including $t_{1}^{*}=t_{2}^{*}=0$ or permanent migrations. In general, there are two possible impacts of an exogenous change in enforcement on migration in this model. First, the exogenous change could affect the optimal number of migrations, e.g. combining two short migrations into a single, longer one, or the reverse. Second, the change could also vary the length of each particular migration, conditional on the number of migrations. In the current analysis I consider only the latter case. I do this because 1), while it is simple, it is sufficient to show that higher enforcement reduces the level of contemporaneous immigration $\left.^{8} ; 2\right)$ I want to focus on repeat migrants to show how changes in future $\left(b p_{2}\right)$, as well as contemporaneous enforcement $\left(b p_{1}\right)$ affect the duration of current migrations $\left(t_{1}^{*}\right)$. Focussing on the second case is equivalent to restricting the optimal migration durations to $t_{1}^{*} \in[0,1)$ and

\footnotetext{
${ }^{5}$ Partial derivatives are sub-indexed with respect to the argument, hence $\partial u / \partial t=u_{t}$.

${ }^{6}$ The assumptions on the utility function ensure that the agents' optimization problem has a maximum.

${ }^{7}$ Note that in the preiod 2 consumption equation the fixed migration cost is only incurred if the individual has returned from his period 1 migration, i.e. $t_{1}<1$.

${ }^{8}$ This result holds also in the second case.
} 
$t_{2}^{*} \in[0,1)$. However, I will discuss the implications of the second case at an intuitive level at the end of this section.

The first-order conditions ${ }^{9}$ for migrants in both periods, i.e. individuals for whom $t_{1}^{*}>0$ and $t_{2}^{*}>0$, are:

$$
\begin{aligned}
& \frac{\partial U}{\partial t_{1}}=u_{t_{1}}+u_{c_{1}}\left(w_{1}^{U S}-w_{1}^{M X}\right)=0 \\
& \frac{\partial U}{\partial t_{2}}=\beta u_{t_{2}}+\beta u_{c_{2}}\left(w_{2}^{U S}-w_{2}^{M X}\right)=0 \\
& \frac{\partial U}{\partial S}=u_{c_{1}}-\beta(1+r) u_{c_{2}}=0
\end{aligned}
$$

One could easily extend this model to allow for future migration costs being a negative function of past migrations or for agents being unable to borrow. In these cases, the magnitude of the migrant flows would differ but the partial effects of enforcement on inflow and outflow would have the same sign.

\subsection{Deterrent effect}

Given preferences, wages, some continuous ability distribution and enforcement levels, agents with different ability levels will choose a different combination of current and future migrations. Individuals whose ability level exceeds a certain threshold $\left(a>a^{h}\right)$ will migrate in both periods. Those with a sufficiently low ability $\left(a<a^{l}\right)$ will never migrate. One can study the impact of changes in migration costs on migration inflow by observing how these ability thresholds change due to higher enforcement. Proving that a marginal increase in border controls increases the values of the existing thresholds shows that higher enforcement reduces migration inflow.

Agents choose in each period whether to migrate or not, and for how long. Using $H$ and $M$ to indicate home stay and migration, which may occur for any positive fraction of the period, there will be four possible outcomes: migration in neither period $(H H)$; migration in one period only (either the second, $H M$, or the first, $M H)$; or migration in both periods $(M M)$. There are six potential ability thresholds (the six possible pairwise combinations of the four different outcomes) that represent individuals indifferent between alternative inter-temporal choices. Only a sub-set of them will be relevant, depending on the values of the parameters and on the type of utility function. For instance, define the ability threshold of the individual indifferent between never migrating and migrating only in the first period as

$$
a_{M H, H H}^{T}=\left\{a \quad s . t . \quad u\left(t_{1 M H}^{*}>0, t_{2 M H}^{*}=0, S_{M H}^{*}\right)=u\left(t_{1 H H}^{*}=0, t_{2 H H}^{*}=0, S_{H H}^{*}\right)\right\}
$$

In order to show the effect of enforcement changes on the inflow of illegal migration, I consider the case in which the values of wages and enforcement are identical in both periods and

\footnotetext{
${ }^{9}$ The second-order condition matrix is negative semi-definite.
} 
$\beta(1+r)=1$. Since the two periods are identical, agents either migrate optimally in both periods or always stay in Mexico, provided that their disutility from staying abroad is sufficiently convex in relation to the migration fixed cost. ${ }^{10}$ Hence, optimal migration duration is the same in both periods $\left(t_{1}^{*}=t_{2}^{*}\right)$, there is no savings, and there is a single relevant ability threshold, $a_{M M, H H}^{T}$, defined by the agent indifferent between migrating in both periods and not migrating in either. Define this agent's ability level as

$$
a_{M M, H H}^{T}=\left\{a \quad \text { s.t. } \quad u\left(t_{1 M M}^{*}>0, t_{2 M M}^{*}>0, S_{M M}^{*}=0\right)=u\left(t_{1 H H}^{*}=0, t_{2 H H}^{*}=0, S_{H H}^{*}=0\right)\right\}
$$

In this scenario, increases in border controls induce the agent to favor the zero migration outcome. To establish this, I can compute the sign of the enforcement effect on ability threshold $\left(a^{T}\right)$ from (1) using the implicit function theorem and the first order conditions. Given that $b p_{1}=b p_{2}=b p$ and that wages and consumption are identical in the two periods, I obtain

$$
\operatorname{sign}\left(\frac{\partial a_{M M, H H}^{T}}{\partial b p}\right)=\operatorname{sign}\left(-\frac{(1+\beta) u_{c^{*}}(\partial M c / \partial b p)}{(1+\beta) u_{c^{*}}(\partial M c / \partial a)}\right)=\operatorname{sign}\left(-\frac{(\partial M c / \partial b p)}{(\partial M c / \partial a)}\right)>0
$$

In practice, the symmetry of the two periods makes the model equivalent to a static one. The above comparative static is sufficient to show that contemporaneous enforcement increases move the relevant ability threshold upwards, causing a deterrent effect on prospective illegal migrants.

While the simple case presented above is sufficient to make my point, more realistic assumptions on variation in costs and benefit of migration and in inter-temporal preferences will result in agents with varying ability endowments being indifferent between alternative options. One case worth mentioning is when variations in enforcement over time cause changes in migration timing: for example, the higher future costs of migration will result in migrations being undertaken in period one rather than in period two. Consider the individual whose utility is maximized by migrating once, irrespective of when the migration occurs. This individual will be induced to migrate in the first period by a marginal increase in future migration costs. The reverse is true in case of an increase in current enforcement levels.

\subsection{Optimal migration duration}

After having shown how enforcement affects the inflow of illegal migration, I now proceed to show its impact on the outflow. I do this by moving back to the more general model and by considering how higher current end future enforcement levels increase the optimal migration

\footnotetext{
${ }^{10}$ Alternatively, agents may prefer to bear the fixed migration cost only once, undertaking only one (longer) migration.
} 
duration in period $1\left(t_{1}^{*}\right)$ of individuals who migrate in both periods. ${ }^{11}$ I examine this effect using comparative statics:

$$
\begin{aligned}
& \operatorname{sign}\left(\frac{\partial t_{1}^{*}}{\partial M c_{1}}\right)=\operatorname{sign}\left(-(1+r) u_{c_{2}^{*} c_{2}^{*}}\left(u_{c_{1}^{*} c_{1}^{*}} u_{t_{2}^{*} t_{2}^{*}}-2 u_{c_{2}^{*} c_{2}^{*}} \Delta^{2}\right)\right)>0 \\
& \operatorname{sign}\left(\frac{\partial t_{1}^{*}}{\partial M c_{2}}\right)=\operatorname{sign}\left(\beta u_{c_{1}^{*} c_{1}^{*}} u_{t_{2}^{*} t_{2}^{*}}+u_{c_{2}^{*} c_{2}^{*}}^{2} \Delta^{2}(2+r)\right)>0
\end{aligned}
$$

where $\Delta$ indicates the wage differential. ${ }^{12}$ These comparative statics show that the optimal migration length is a positive function of both current and future levels of border enforcement. These results are intuitive: because of the concavity of the utility function, higher costs of migrating lengthen the time one must spend abroad to reap positive returns from the migration. One would obtain the same result by replacing the assumption of concave utility with target earning behavior: as migration costs increase, it takes longer to save the desired amount of money.

Migration duration is also a positive function of future migration costs: for individuals who migrate in both periods, a marginal increase in future enforcement levels will increase optimal current migration duration. Illegal agricultural workers, who, with low enforcement levels, would undertake two short trips in each period during harvest season, may be induced to stay in the U.S. also between seasons because the cost of future migration has risen. In practice, given the large stock of highly mobile undocumented resident U.S. migrants, both these effects may be substantial in size.

To summarize, modeling the effect of border enforcement on choice and duration of repeated temporary undocumented migrations shows that border controls have a deterrent effect on prospective migrants: higher enforcement levels raise migration costs, causing fewer people to migrate. However, tighter enforcement affects also the behavior of current migrants, who will stay for longer time in the destination country. An increase in contemporaneous costs requires migrants to stay longer before they can benefit from the investment. Higher future enforcement also induces current migrants to delay their return because future trips are more costly. These results imply that the effect of an increase in border policing on the net flow of illegal migration is ambiguous and depends on the amount of both prospective and current migrants and on how sensitive both groups are to changes in migration costs.

These findings have several other implications: first, policy-induced changes in illegal migration inflow differ from changes in its stock, because the policy has also a significant effect on

\footnotetext{
${ }^{11}$ Changes in future migration costs do not affect the current migration duration of individuals who migrate only in period 1 .

${ }^{12}$ This assumes that wage differentials are identical in the two periods. This simplifies the notation without changing the signs of the partial derivatives.
} 
migration outflow. Second, the estimated effect of the policy observing only migration inflow is larger than the true one (in absolute value). Hence, judging the effectiveness of border enforcement only by assessing its impact on the inflow results in an overestimate of the true effect. This may result in too much spending being devoted to border enforcement and too little to alternative policies, thus providing an additional explanation for the observed disproportionate resource allocation in favor of border (as opposed to interior) enforcement. Lastly, for each level of prospective migrants, the optimal level of border enforcement is a function of the stock of current U.S.-based illegal migrants.

As I argue later in the paper, the may result from using its estimated impact in the migration inflow reduction as a proxy for its effect on migrant stock. If the effect on the inflow is an overestimate of the impact on the stock (which is the case if illegal migrants lengthen their permanence in the U.S. in response to higher border enforcement) then border enforcement may appear more effective than it actually is, and attract larger funding.

\section{The data}

Table 1 describes the data used, providing their means and standard deviations for the period of interest. The data used come from several different sources: border enforcement and aggregate apprehension data are from unpublished records of the Immigration and Naturalization Service (INS), the Department of Justice agency managing border enforcement. U.S. wage and unemployment data are from the Bureau of Labor Statistics. The Mexican unemployment rate is from World Economic Outlook (WEO) data. The other Mexican macroeconomic variables used are from the Mexican National Statistical Institute (INEGI). ${ }^{13}$ Hanson and Spilimbergo (1999b) describe both the enforcement and the macroeconomic data in great detail.

Individual migration information comes from the Mexican Migration Project database (MMP71). The MMP71 sample contains data from 71 communities in 13 different Mexican states between 1987 and $1998 .{ }^{14}$ Every year a number of different Mexican communities (normally 5) are selected in such a way as to represent a range of diverse characteristics (size, ethnic composition, location and economy). ${ }^{15}$ Interviewers collect data on a random sample of 200 households from each locality between December and January, months in which migrants tend to return home. I

\footnotetext{
${ }^{13}$ With the exception of the devaluation rate, which is from aggregate MMP71 data.

${ }^{14} \mathrm{I}$ also include data on a small sample of pilot interviews from 1982.

${ }^{15}$ Each year, a series of U.S.-based non-random follow-up interviews are undertaken in the summer months, using snowball sampling (a method whereby interview subjects are indicated by previous interviewees). I discard this much smaller group from the analysis because it is selected through a non-probabilistic sampling methodology, although Massey and Zenteno (1999) analyze the quality of the data, and conclude that they are generally a representative source of information on Mexico-U.S. migration.
} 
Table 1: Descriptive statistics of the variables used, November 1998 data.

\begin{tabular}{|c|c|c|c|}
\hline \multirow[b]{2}{*}{ Name } & \multicolumn{2}{|c|}{$1972-1993$} & \multirow[b]{2}{*}{ Description } \\
\hline & Mean & St. Dev. & \\
\hline Linewatch hours & 2.15 & 0.51 & Million annual hours of border control \\
\hline Illegal migrations & 0.035 & 0.007 & Proportion of sampled individuals undertaking an illegal migration \\
\hline Returns & 0.551 & 0.044 & Proportion of sampled individuals returning from an illegal migration \\
\hline US unemployment & 6.84 & 1.30 & U.S. unemployment rate \\
\hline US wage in pesos & 29.53 & 5.86 & $\begin{array}{l}\text { U.S. real hourly wage rate in the } \\
\text { private sector, } 1990 \text { pesos }\end{array}$ \\
\hline MX wage index & 1.09 & 0.16 & $\begin{array}{l}\text { Mexican real hourly manufacturing wage } \\
\text { index, production }(1990=1)\end{array}$ \\
\hline DEA budget & 495.25 & 241.91 & $\begin{array}{l}\text { Drugs Enforcement Agency real budget, } \\
1990 \text { million dollars }\end{array}$ \\
\hline Legalizations & 25.95 & 43.86 & Annual MMP71 Mexican legalizations \\
\hline Apprehension & 540.54 & 216.09 & annual INS border apprehensions (in thousand) \\
\hline
\end{tabular}

observe the complete migration history of household heads. For instance, I observe 30 years of information regarding the timing, duration and location of migration of an individual aged 30 when interviewed at time $t$. If the household head is absent, the interviewer collects the relevant information on his/her current and past migrations from other household members (Colussi, 2004). Interviewees include individuals with past spells of migration (both legal and illegal ones) as well as others who never migrated. Massey (1987) provides further details about the study design.

I build a panel from household heads' retrospective migration histories. The interviews were done between 1987 and 1998 and they collect recall data that span several decades. Because my instrumental variable only starts being observed in 1972 (the year in which the Drug Enforcement Administration was created), I only study migration decisions starting from that year. In addition, to limit recall errors, in some specifications I use a maximum 15 year recall window prior to the interview. Hence, the sample contains the 1972-1987 migration history of individuals interviewed in 1987, or, for instance, the 1976-1990 migration history of 1990 interviewees when using maximum 15 years recall data. I only use migration data through 1993, because the available data for the last five years of the sample (1994 to 1998) consist of too few observations to be included.

I include individuals aged between 16 and 55, who do not receive a disability pension and cannot migrate legally. In such a way, I obtain an unbalanced person-year panel with different 
entry and exit years. For example, suppose I observe a household head aged 67 in the interview year, 1997. His migration history is in the sample only between 1972 (1983 when I use up to 15 years recall period) and 1985 (because he turns 56 in 1986).

Figure 1 exhibits my key explanatory variable, annual border enforcement level, measured in million linewatch hours. ${ }^{16}$ This Figure shows that border controls increase over time, with particularly steep increases in the late 1970's and from 1986.

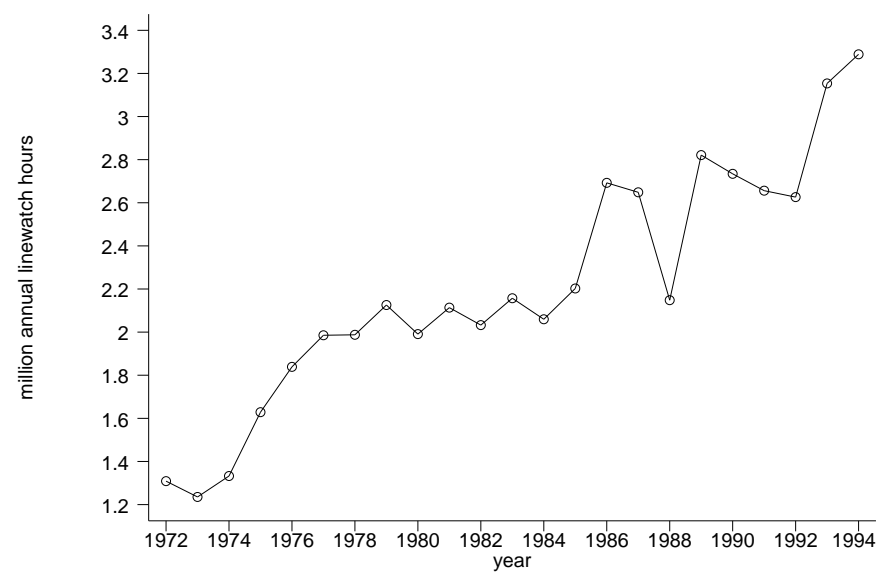

Figure 1: Border Patrol - million linewatch hours

The average intensity of border controls between 1986 and 1993 is $20 \%$ higher than during 19771985. This is a consequence of the 1986 Immigration Reform and Control Act (IRCA). One of the Act's various measures to curb illegal immigration was the increase in border policing, together with sanctions for the employment of undocumented labor and an amnesty program to legalize a large group of current illegal U.S. residents. ${ }^{17}$ The implementation of IRCA was partly a reaction to the increased migration incentives caused by the economic and financial crisis that hit Mexico in the early 1980s. With high inflation levels eroding the purchasing power of wages $^{18}$ and periodic peso devaluations, more individuals were attempting to work illegally in the United States. The two panels in Figure 2 show how the relative peso value of Mexican versus U.S. wages declined dramatically during this period. This substantial time variation is useful to identify wage effects on migration.

The impact of the Mexican economic crisis on incentives to migrate is also noticeable in

\footnotetext{
${ }^{16}$ By linewatch hour I mean one hour of patrolling duty along the southwestern U.S. border.

${ }^{17}$ Border Patrol budget, which has been increasing continuously since 1986, does not reflect the 1988 sharp linewatch hours decrease. Inspection of the monthly linewatch data shows that the lower enforcement in 1988 is concentrated in the month of August. The enforcement intensity of the remaining 11 months is closer to 1987 and 1989 levels. Unfortunately, migration data are at the annual level only.

${ }^{18}$ Mexican real minimum wage decreases by $74 \%$ in the first half of the 1980 s (Hanson and Spilimbergo, 1999).
} 

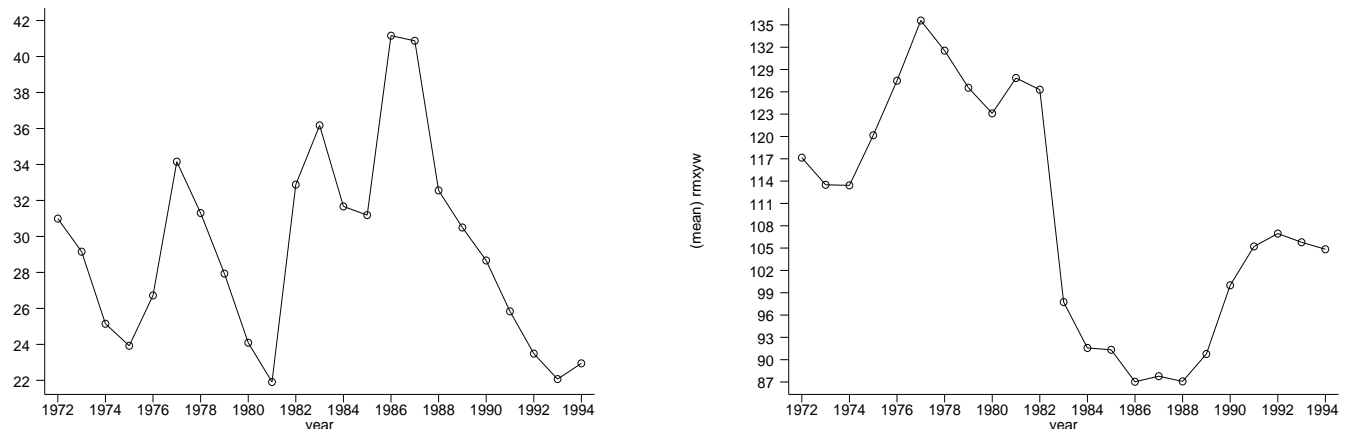

Figure 2: U.S. hourly private sector wage in 1990 pesos (left) and Mexican real manufacturing hourly wage index $(1990=100)$

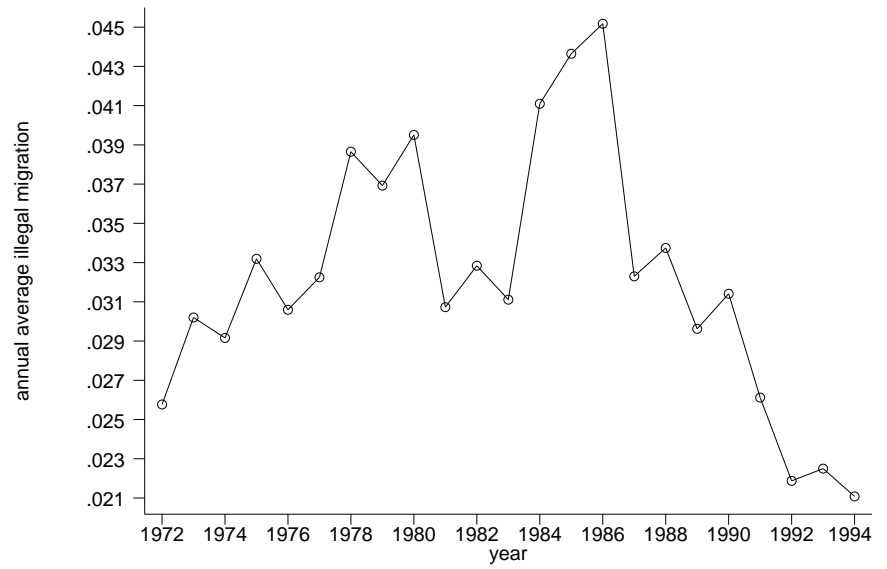

Figure 3: Proportion undertaking an illegal migration out of potential migrant population 
Figure 3, which shows sample illegal migration inflow to the United States as proportion of overall population of potential migrants. This variable is created considering the sample of potential migrants who are in Mexico, and computing the fraction of potential illegal migrants who begins an illegal migration to the United States in each year. The proportion of individuals who migrate nearly doubles between 1972 and 1986, with a peak in 1985-1986. The rising migration trend reverses starting in 1986. Part of this effect is likely a consequence of the IRCA amnesty granted to more than two million U.S.-based illegal Mexicans migrants: this results in a large group of individuals simply switching from illegal to legal status. ${ }^{19}$ The improvement of Mexican economic conditions, the toughening of border enforcement, and the introduction of employer's sanctions are also additional likely determinants of the trend reversal.

Figure 4 shows average annual returns from illegal migrations. In this case, I consider the sample of migrants who are illegally in the United States. I measure the fraction of this groups who leaves the U.S. to return to Mexico each year. Up to 1985, there is an upward sloping trend, i.e. an increase in short-term temporary migration. This may be generated by migration volume's growing faster than border enforcement, as shown in the Figures above, which would result into lower individual apprehension probability.

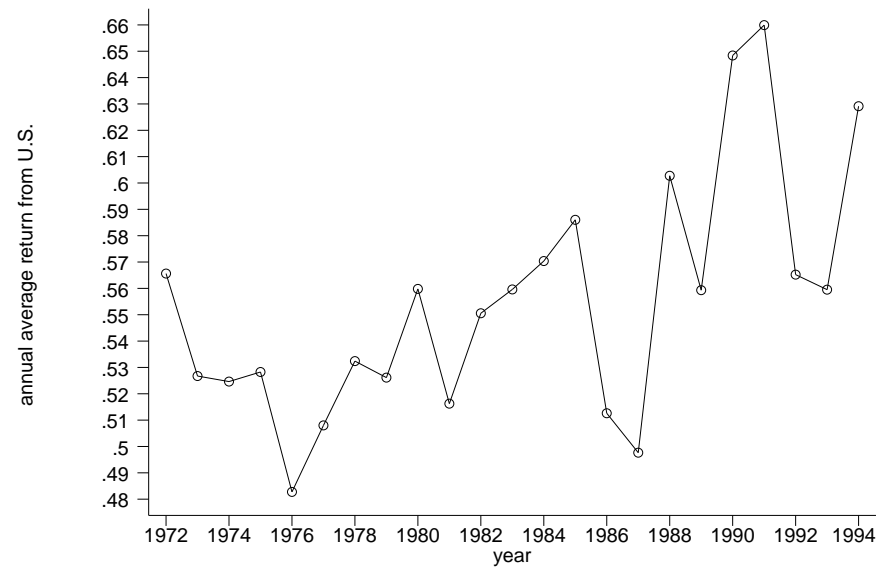

Figure 4: Proportion of current undocumented migrants returning from an illegal migration

The amnesty program, as well as the tighter border controls, may explain the sharp decrease in 1986 and 1987 returns. This may be because amnesty applicants might refrain from returning to Mexico while waiting for their legalization application to be processed, i.e. approximately between 1986 and $1988 .^{20}$ The last 5 years do not show a clear trend in returns from illegal

\footnotetext{
${ }^{19}$ INS estimates a total of 2,600,000 Mexican legalizations (Statistical Handbook on U.S. Hispanics, 1992), while Bratsberg (1995) reports nearly 2,200,000 ones.

${ }^{20}$ There is a 12 -month window to apply for the legalization and it takes several months for the authorization
} 
migrations. Average returns are now proportionally higher than pre-IRCA ones, although one may attribute it to the change in illegal migrant mix: longer-term undocumented migrants are now legal (eligible applicants must prove they had been living in the United States since 1982), and this leaves a larger proportion of short-term migrants.

There are various wage measures that might affect migration decisions. I observe both minimum wages and some measures of private sector wages. In particular, I have data on U.S. average hourly minimum wage and Mexican monthly average minimum wage; and on U.S. hourly private sector wages and on an index of Mexican average production manufacturing hourly wage. The advantage of conditioning on minimum wages is that they may provide an upper bound to the wage paid to unskilled, illegal migrants. ${ }^{21}$ Private sector wages, instead, have more time variation and are likely to be more responsive to changes in labor supply and demand. I chose to condition on private sector wages for these reasons, and also because minimum wages appear to be highly multicollinear with the other explanatory variables in the regressions. ${ }^{22}$ In any case, the trends of minimum and private wages are not too dissimilar.

\section{$5 \quad$ Survey design and data issues}

Four characteristics of the survey design may cause a bias in the estimated effect of enforcement on illegal migration net flow. The first two are different types of non-random sample selection: the absence of some current migrants due to data being collected in Mexico only, and the fact that the sampled communities may not be representative. The remaining two are the recall bias associated with the use of retrospective data, and the use of an unbalanced panel to identify the effect of longitudinal variation in enforcement. ${ }^{23}$

The most important source of potential bias is caused by data being collected in Mexico. Although I observe household heads' migration history even if the person is absent at the time of the interview, no information is available when the whole family is away. Some of the household heads missing from the data are illegal migrants in the United States whose family joined them.

\footnotetext{
to be granted.

${ }^{21}$ Illegal migrants are mainly unskilled individuals: average education level for the population of potential migrants is 5.1 years, whereas Hanson and Spilimbergo (1999b) report that mean school years for individuals employed in manufacturing in Mexico was 8.1 in 1990.

${ }^{22}$ The analysis of the correlations between both sets of wages and the other variables used in the econometric model show that the multicollinearity arising from the use of minimum wages cannot be directly related to any pairwise correlation.

${ }^{23}$ Munshi (2003) has a very good discussion of potential data issues caused by the MMP survey design, applied to a different context. Some estimation issues are common to both exercises. I refer the interested reader to this additional source.
} 
This is likely to bias estimates of the effect of border enforcement on illegal migration inflow and outflow, albeit to different extents. The magnitude of the bias on the inflow is likely to be small for two reasons. First, the heads of missing households are likely to be a small proportion of the observed group of potential migrants, given my very loose definition of potential migrants. Second, households who have left Mexico to join the head in the United States are likely relatives of long-term migrants who are sufficiently established in the Unites States to have their families join them. These household heads' migrations happened in the past, hence a fraction of them must have occurred before 1972. Finally, after migrating these household heads are no longer part of the sample of potential migrants anyway.

Missing data are more problematic for the effect of enforcement on illegal migration outflow. The missing household heads are a larger fraction of the sample of current illegal migrants. Moreover, if unobserved heads are long-term illegal migrants, they may be the least sensitive to enforcement changes. Hence, the estimated effect of enforcement on the likelihood of returning from illegal trips may be larger (in absolute value) than the true one.

A second characteristic of the data that may cause selection problems is the non-randomness of the communities sampled at the beginning of the project: the localities chosen in the first years of the project's existence belong primarily to high migration areas. This may result in migrants being over-represented. If individuals with no prior migration experience nor access to migrant networks are the most sensitive to enforcement tightening, then their limited presence in the sample may bias the parameters of interest downward (in absolute value). However, in more recent years the MMP began sampling also different types of communities. Since the data used are retrospective, I can use 1970s and 1980s migration data from localities sampled in the 1990s. This should partially offset the potential downward bias.

There is no direct way to assess how the sample selection affects the estimates of the parameters of interest. Ideally, one would want to compare the sampled individuals with the missing ones and see whether their decisions to undertake and return from illegal migrations differ systematically in ways related to border enforcement. One indirect way to test for the sample representativeness is to compare estimates of illegal migration inflow and growth computed using the MMP71 data and alternative sources. These tests address both the issue of missing migrants and the one of the non-randomness of the communities sampled in the first years of data collection.

I first compare the inflow estimates computed from different sources, shown in Figure 5. I obtain an estimate of the amount of annual immigration by comparing sample and aggregate border apprehensions. Sample data are from the MMP71. Aggregate apprehension data are from INS records. Knowledge of sample annual apprehension rate $\bar{a}=a / m$, where $a$ is total sample 
apprehensions and $m$ is sample undocumented migrations, and of aggregate yearly apprehensions $A$ permits to estimate the annual Mexican illegal migration inflow:

$$
I=\frac{A}{\bar{a}}
$$

The corresponding estimated volume of illegal migration ranges between $234,000^{24}$ and 2,570,000 individuals in the years between 1972 and 1993, with an annual average of 1,265,000.

The first alternative inflow estimate I consider is the one computed by Massey and Singer (1995), who use only the 22 MMP communities sampled between 1987 and 1992. I expect their estimates of the illegal migration inflow to be higher than the ones computed from MMP71 because their data come from localities with high intensity of migration. The volume of illegal Mexican migration estimated using MMP71 data is consistently lower than the one computed by Massey and Singer (1995): it ranges between 35 and $77 \%$ of their estimates, in line with expectations. Nevertheless, the trends of the two series are not dissimilar, although migration growth in the first half of the 1980s is more marked using Massey's and Singer's figures.

I obtain an additional estimate of illegal migration inflow following Espenshade (1995b), who notes how the ratio of undocumented migrations and total border apprehensions is stable between 1977 and 1988 and amounts to 2.2. Multiplying this ratio by the INS aggregate apprehension data results in a migration inflow that averages 1,323,000 between 1977 and 1988. Mean undocumented immigration for the same period using the MMP71 estimates is about $95 \%$ of the Espenshade-based figure. The similarity between the two series is striking, and the difference might be entirely imputed to non-Mexican illegal migration.

As a further robustness check, I also compute average annual illegal migration inflow discarding data collected in 1987, 1992 and post-1993 survey years (corresponding to important policy changes), on the grounds that the interviewees' migration behavior may be affected by the policy changes. The two series are nearly identical up to 1987, and differ between 1988 and 1991, when, however, there are few available observations for the smaller sample.

I now compare the MMP71 estimates of the annual growth of undocumented Mexican population in the United States with INS aggregate data. I obtain an estimate of migration growth from MMP71 data by computing the sample annual illegal migrants departure rate from the U.S. as a fraction of entries, $f$. For example, if in a given year there are 200 illegal entries and 160 exits, the corresponding $f$ equals 0.80 . The change in stock is $(1-f) I$, where $I$ is aggregate inflow. The rate $f$ amounts to $95 \%$ for the whole sample, implying an average annual outflow of 1,202,000. The INS Statistical Yearbooks estimate that the population of U.S.-based Mexican illegal migrants grew from 1.1 to 2 million between 1980 and 1990. This corresponds

\footnotetext{
${ }^{24}$ All figures have been rounded.
} 


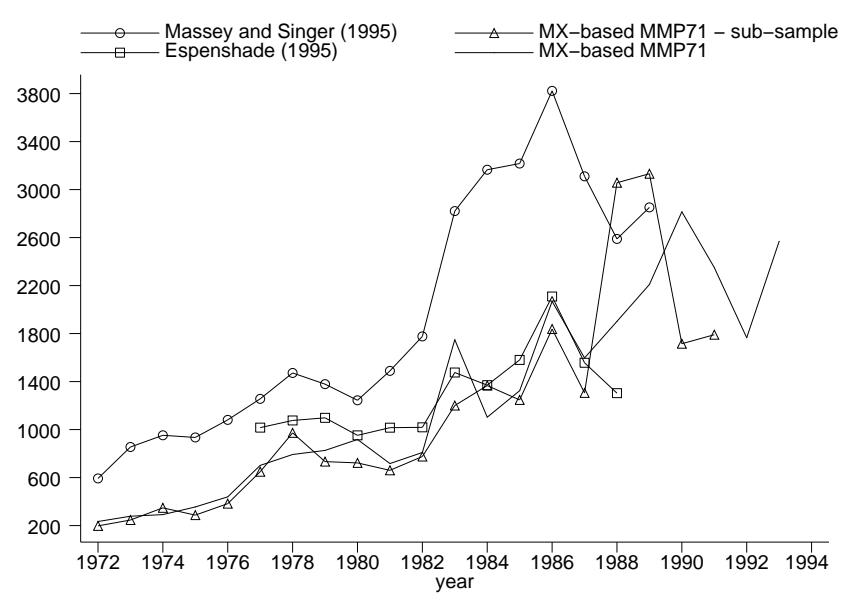

Figure 5: comparison of various estimates of illegal migration inflow (in thousands)

to an average annual increase of 90,000. Using the method described above, I calculate that the average annual growth in the illegal population stock using MMP71 data for the same years is 87,000 .

To summarize, the evidence provided so far is by no means a proof of the absence of sample selection, but it supports the view that it may be small or negligible, especially concerning illegal migrant inflow. There may be an upward bias in the estimates of the effect of enforcement on migrant outflow. Therefore, one can interpret the estimated effects of border controls on illegal migrant outflow as upper bounds (in absolute value) of the true parameters.

An additional estimation issue may be generated by the retrospective nature of the data. The presence of recall bias in the dependent variable will not bias the estimates of the effect of enforcement on migration inflow and outflow, unless the errors are systematic and vary over time (e.g. individuals forgetting about having migrated as a function of the recall period), resulting in a spurious correlation with border enforcement. However, as also noted by Munshi (2003), one expects individuals to provide accurate responses, given the basic nature of the information collected (which is whether the individual was in Mexico or in the United states in a given year, and in the latter case, whether with legal or illegal status). Thus, it is unlikely that individuals systematically under- (or over-) report migrations. To verify this, I provide estimates of the effect of enforcement alternatively using all valid observations and limiting the recall period to a maximum of 15 years.

Finally, note that the number of observed individuals varies in each year, because of the sampling scheme. For instance, the size of potential migrants varies from a minimum of 136 in 1972 to a maximum of 7379 individuals in 1985. Hence, if the effect of enforcement varies over time and one does not re-weight the observations appropriately, the estimated parameters would 
differ from the average partial effects of enforcement over the observed time period. I deal with this issue by re-weighting each observation by the inverse of the observed probability of being sampled in a given year. ${ }^{25}$

\section{Empirical specification and estimation issues}

The model has clearly highlighted the ambiguous effect of border enforcement on the net inflow of illegal migration. I now proceed to estimate the observed magnitude of the effect for the 19721993 time period. My empirical approach consists of estimating the effect that changes in border controls have on the individual probability of transition between different states: from staying in Mexico $(m=0)$ to becoming an illegal migrant $(m=1)$; and from being an undocumented U.S. resident $(r=0)$ to returning home $(r=1)$. Time is discrete and the unit is the year. I model the two transitions separately. $i$ indicates the $i$-th individual and $t$ the year.

I use the MMP data to create the two dependent variables: $m_{i t}$ takes the value of zero for every year the individual is in Mexico, and of one when the individual migrates to the United States; $m_{i t}$ is missing for all subsequent years the person spends abroad. If the individual returns to Mexico and meets the aforementioned requirements, he or she is again included in the sample. $r_{i t}$ is zero for every year an individual lives illegally in the U.S.A., and one in the year the migrant returns home. The variable is missing for all years spent in Mexico between intermediate migrations. ${ }^{26}$

Separately estimating the enforcement effect on inflow and outflow is more useful, from a policy perspective, than looking at the effect of border policing on the net flow directly. For instance, suppose the enforcement effect on the net flow of illegal migration is zero. Policy implications could still depend on how much inflow and outflow are sensitive to increases in the enforcement level. In case they both are, enforcement "works" and one may want to increase enforcement and provide further incentives for illegal migrants to leave the United States. If both flows are not affected by enforcement changes, border policing "does not work"; the policy maker would have to look for different policies to stem illegal migration.

\footnotetext{
${ }^{25} \mathrm{I}$ also estimate the effect of enforcement using time-series data, where possible. This is explained in further detail below.

${ }^{26}$ There are roughly 10,000 potential migrants, corresponding to about 135,000 person-year units in the sample. About $85 \%$ of the sampled individuals never migrates in the observed years. The average number of migrations for those who migrate is 2.49 , while the maximum number of observed illegal trips for the same individual is 22 .
} 


\subsection{Estimating the likelihood of migrating illegally}

The previous section has shown that migration decisions depend on economic differentials between Mexico and the United States and on the level of border enforcement. I use a linear probability model to specify the likelihood that a potential illegal migrant undertakes a migration at time $t$, as a function of the variables affecting the costs and benefits of migration considered in the theoretical model:

$$
m_{i t}=\alpha^{m}+\beta^{m} b p_{t}+\gamma^{m} X_{t}+u_{i t}^{m}
$$

where $m$ is a dichotomous variable that takes the value of one when an individual leaves Mexico to undertake an illegal migration, $b p$ is border enforcement and $X$ contains macroeconomic variables that influence the migration decision and are potentially correlated with border controls. These variables are: the U.S. private sector hourly real wage rate in pesos and an index of Mexican manufacturing real hourly wage, together with U.S. unemployment, to capture the probability of finding a job once in the United States. The number of individuals who obtain legal status is added as well $(l)$. Since legalizations and enforcement increase at the same time in the second half of the 1980s, as they are both IRCA provisions, it is important to disentangle these two effects. The higher the legalization number, the lower the volume of both actual and potential illegal migrants. Thus, part of the post-IRCA decline in both undocumented border crossings and returns from illegal migration is simply the result of a status change, i.e. becoming a legal resident, rather than the direct consequence of tougher enforcement. This effect may be substantial, since more than 2 million Mexicans are estimated to have benefited from the IRCA legalization program.

I consider $u_{i t}^{m}$ as a composite error term,

$$
u_{i t}^{m}=\mu_{i}^{m}+\lambda_{t}^{m}+\varepsilon_{i t}^{m}
$$

where $\mu_{i}^{m}$ and $\lambda_{t}^{m}$ represent all individual- and time-specific factors that influence the migration decision and are not captured in the theoretical model, while $\varepsilon_{i t}^{m}$ is some white-noise disturbance. The parameter of interest is $\beta^{m} .^{27}$

Border controls may be endogenous, as the enforcement level may be correlated to unobservable shocks to migration. For instance, a lack of political stability in Mexico may provide additional incentives to migrate to the United States. Border enforcement may be tightened

\footnotetext{
${ }^{27}$ Migration is likely not to be a static decision: decisions may depend on both the current environment and on expectations of the future environment. While the econometric specification in (4) is not explicitly dynamic, one can think of its coefficients as the reduced-form coefficient of a dynamic model where migration depends on both current and expected future values of the relevant variables. Hence $\beta^{m}$ would be the net effect that a marginal increase in current enforcement has on the migration likelihood through both current and expected
} 
in response to the anticipated higher migration inflow. This point was first made by Hanson and Spilimbergo (1999b). In order to address this issue, I propose to use Drugs Enforcement Administration (DEA) budget as instrumental variable. Drugs are smuggled in massive quantities through the U.S. Southern border, and one of the aims of border patrol is also to curb narcotics trafficking. The basic idea behind the use of this instrument is the following: border linewatch hours depend on U.S. preferences over migration and drug trafficking. The first source of variation is certainly endogenous, while the second one is potentially exogenous. Changes in U.S. distaste for drugs simultaneously increase DEA budget and border linewatch hours. This is consistent with the empirical evidence: border linewatch hours and DEA budget show a high and significant positive correlation (85\%) and the coefficient of DEA budget in the first-stage equation is always positive and strongly significant. The instrument is valid if changes in DEA are uncorrelated to shocks to migration. I cannot formally test the latter identification assumption. However, I will try and provide indirect evidence of the absence of such correlation. For example, I cannot observe whether DEA budget is correlated to unobservable shocks to the Mexican economy that change the incentives to migrate, but I can check whether there is a correlation between DEA budget and observable Mexican macroeconomic variables. I regress DEA budget on enforcement on U.S. and Mexican wages, U.S. unemployment rate and Mexican currency devaluations. The Mexican variables are not significantly correlated with DEA budget. The instrument would also be invalid if the drugs and illegal migration markets were related (for instance, migrants may smuggle drugs to the United States to finance their trip). In that case, an exogenous change in drug prices, for example, may contemporaneously affect both illegal migration and the DEA budget. I am not aware of direct evidence of the separation of the drugs and illegal migration markets. However, indirect and anecdotal evidence regarding the time period covered by the sample abounds. A recent survey by The Economist (2005) reports that in the last few years the two markets have begun overlapping, with some migrant smugglers

future migration costs.

$$
\beta^{m}=\frac{\partial P\left(m_{i t}=1 \mid m_{i t-1}=0\right)}{\partial b p_{t}}+\sum_{s=t+1}^{T} \frac{\partial P\left(m_{i t}=1 \mid m_{i t-1}=0\right)}{\partial E\left(b p_{s}\right)} \frac{\partial E\left(b p_{s}\right)}{\partial b p_{t}}
$$

considering a linear probability model for simplicity. One expects the first term $\frac{\partial P\left(m_{i t}=1 \mid m_{i t-1}=0\right)}{\partial b p_{t}}$ to be negative, and the following ones, $\frac{\partial P\left(m_{i t}=1 \mid m_{i t-1}=0\right)}{\partial E\left(b p_{s}\right)}$, positive, with a negative net effect. In a previous version of the paper I estimated also a model where current migration decisions are affected by future as well as current levels of enforcement and macroeconomic variables. The estimated coefficients are consistent with the above discussion: higher current enforcement reduces the likelihood of undertaking a contemporaneous migration by decreasing its costs. However, agents anticipate future enforcement to be higher too. This effect increases the likelihood of a current migration by a smaller magnitude than the direct effect on current costs. These results are not presented here, but are available upon request. 
having illegal border crossers carry drugs, but that the phenomenon is quite recent. In the time period covered by my data, migrant smugglers are primarily former migrants and do not belong to sophisticated organizations.

I have also tried alternative instruments. I considered dummies to control for the political party of the current U.S. president, and a variable that indicates whether both Senate majority and U.S. president are Republican. The significance of these latter variables suggests that border enforcement resource allocation may be influenced by the political cycle. ${ }^{28}$ However, it is possible that the former variables directly affect migrants' propensity to move to the United States. I also considered the number of years to a presidential and congressional election as additional instruments, but the significance of these additional regressors is not very high in the first-stage regression. ${ }^{29}$ Given the fact the the validity of these further instruments is questionable, and that the IV estimates of the parameter of interest are not affected by their exclusion from the first-stage equation (once I condition on DEA budget), the result section reports only output obtained using DEA budget as instrumental variable.

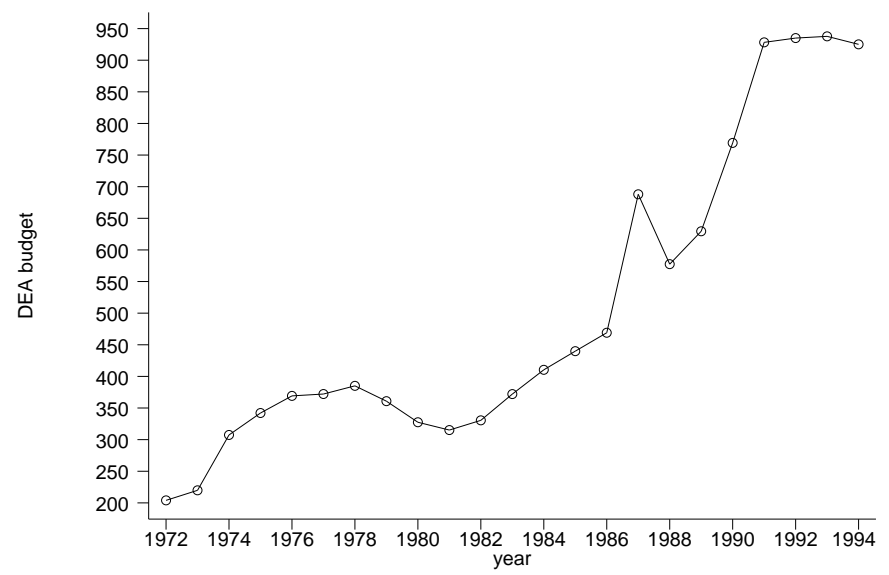

Figure 6: Drugs Enforcement Administration budget, 1990 million USD

An additional issue is posed by the selection of interviewees caused by the sample design. As explained in Section 5, there is no information on migrants when the whole household moves. If migrants are selected in some way related to border enforcement, this will result in a correlation between the annual mean of $\mu_{i}^{m}$ and $b p_{t}$. However, if the bulk of Mexican illegal migration is constituted by temporary moves, with individuals migrating on their own, and leaving their

\footnotetext{
${ }^{28}$ There is a significant higher enforcement level when both majority senate and president are Republican. Moreover, patrol of the border is lower in presidential election years, when the outgoing president is Republican.

${ }^{29}$ When I use monthly levels of border enforcement rather than annual one, the significance level of month-toelection variables is much higher. Unfortunately, monthly migration data is not available.
} 
family behind, one expects the magnitude of the bias to be small, if not negligible.

Further estimation issues are, first, that shocks to migration may be serially correlated, as already noted by Hanson and Spilimbergo (1999). Shocks may be persistent, they may reach the farthest regions with a lag, or individual reaction to them may be delayed. I control for serial correlation by modeling the error term as generated by an $\mathrm{AR}(1)$ process. Second, that each year has a different number of observations. I re-weight the observations to insure that I am estimating the average partial effect of enforcement on illegal migrant inflow between 1972 and 1993.

I estimate equation (4), representing the individual likelihood of becoming an illegal migrant at time $t$, using a linear probability model (LPM). I interpret the estimated coefficients in the LPM as local linear marginal effects at the mean of the explanatory variables. The standard errors are always clustered at the year level to consider the variation in the aggregate error term $\lambda_{t}^{m} \cdot 30$

\subsection{Estimating the likelihood of returning from an illegal migration}

The theoretical model predicts that optimal migration duration is a function of enforcement levels and of economic differentials. I express the relationship between migration costs and duration in terms of the individual likelihood of returning home. Hence, if migrations are lengthened by higher costs, I expect the return probability to be a negative function of the latter.

For individual $i$ in time period $t$, the probability of returning from an illegal U.S. trip conditional on being an undocumented U.S. resident is described by the following linear probability model

$$
r_{i t}=\beta^{r} b p_{t}+\gamma^{r} X_{t}+\sum_{j=1973}^{1993} \delta_{j}^{r} c_{j}+u_{i t}^{r}
$$

The dependent variable, $r_{i t}$ is zero for current illegal migrants who do not return home, and one for those who leave to Mexico in time $t$. $\beta^{r}$ measures the marginal effect of enforcement on the likelihood of returning from an illegal U.S. trip. ${ }^{31}$ The set of $X$ variables is the same as used in

\footnotetext{
${ }^{30} \mathrm{I}$ also estimated a probit model, relaxing the assumption that the conditional probability is linear in the parameters. I addressed the endogeneity issue in a non-linear framework by adopting Blundell and Smith's (1986, 1989) control function approach, computing block-bootstrap estimates of the coefficient standard errors of both border controls and residuals from the first-stage regressions. I did not present these results because the estimated probit standard errors are biased in the presence of heteroskedasticity. However, the LPM and probit point estimates are remarkably similar in magnitude.

${ }^{31}$ Again, the parameter of interest can be interpreted as the sum of the direct and indirect effect of changes in border enforcement on the likelihood of returning to Mexico. Both effects are expected to be negative, as
} 
the migration likelihood equation.

As before, the error term can be decomposed into an individual-specific effect, $\mu_{i}^{r}$, a timevarying effect, $\lambda_{t}^{r}$, and a white-noise disturbance, $\varepsilon_{i t}^{r}$ :

$$
u_{i t}^{r}=\mu_{i}^{r}+\lambda_{t}^{r}+\varepsilon_{i t}^{r}
$$

There are now two main sources of potential endogeneity. One is the possibility that the level of enforcement may be responsive to shocks to outflow $\lambda_{t}^{r}$. As in the previous case, I address this issue by using DEA budget as an instrumental variable. The other one is due to sample selection. The decision to migrate depends on the intensity of border controls. Higher migration costs select migrants with "better" observable and unobservable characteristics (in the sense that their migration is profitable despite the higher costs). Hence, the unobserved characteristics of incoming migrants are likely to be positively correlated with enforcement. This is a cohort effect.

I believe I cannot deal with this additional source of endogeneity using an instrumental variable approach. While in the case of endogeneity due to unobserved shocks to migration it is possible to think of separating the part of the enforcement variation that does not depend on aggregate shocks, in the selection case any variation in enforcement causes a change in the composition of migrants. Alternatively, one could try and find exclusion restrictions that affect the likelihood of migrating but not that of returning from a migration. These restrictions are hard to find. Hence, I propose a different identification approach. I add a set of cohort dummies, $c_{j}$ with $j=1973, \ldots, 1993$, as further conditioning variables in 5 . I define the cohort by the year of arrival in the U.S.; for example, $c_{1990}=1$ for all individuals who entered the U.S. in 1990. ${ }^{32}$ In this way I am controlling for the average migrant characteristics in their year of entry. The remaining deviations from means, which are captured by the composite error term, should be uncorrelated with the enforcement level. One advantage of this approach is that I can indirectly observe the effect of enforcement on migrant selection by observing how the enforcement coefficient changes after adding the cohort dummies.

I estimate (5) by LPM using DEA budget as instrumental variable to account for the correlation between bp and $\lambda_{t}^{r}$. Again, I cluster the standard errors at the year level, and interpret the estimated coefficients as local linear marginal effects at the mean of the explanatory variables.

\section{Results}

Table 2 reports OLS and IV estimates of the marginal effect of border enforcement on the likelihood of undertaking an undocumented migration. Even-numbered columns provide instru-

confirmed by a set of estimations not reported here but available upon request.

${ }^{32}$ The base category is 1972 and earlier. 
mental variable (IV) estimates of the parameter of interest. The regressions in the first two columns are estimated using the whole available sample between 1972 and 1993 . Columns 3 and 4 restrict the valid cases to a maximum of 15 years recall period; columns 5 and 6 use the same restricted sample, but re-weight the observations multiplying them by the inverse of the probability of being sampled in each year. Finally, the last two columns provide estimates of the effect of enforcement on aggregate inflow: the dependent variable is the fraction of individuals who undertake an illegal migration each year.

Border control is measured in million linewatch hours. The Durbin-Watson test confirms that the errors are serially correlated, hence I model the residual as generated by an $\operatorname{AR}(1)$ process. ${ }^{33}$ The results are in line with the prediction of a negative effect of current enforcement on the likelihood of migrating illegally. The instrument is positively correlated with enforcement in the first-stage equation and it is significant at the $1 \%$ level. The significance of the Hausman test provides evidence of the inconsistency of the linewatch coefficient, when the endogeneity of enforcement is not taken into account. The upward biased OLS results suggest that there is a positive correlation between border patrol and aggregate shocks, consistent with the idea that the level of enforcement is set according to the expected intensity of the migration flow.

My preferred results are the ones from column 6: since I re-weight the observations to give each year equal weight, these results provide an estimate of the average 1972 to 1993 partial effect of enforcement on migration likelihood that is robust to the presence of time-varying returns to border controls. Using these estimates, a one million increase in annual linewatch hours reduces the likelihood of undertaking an undocumented migration by 1.3 percentage points. Given that the average annual migration volume amounts to 4 percent of potential illegal migrants in the sample, this enforcement increase reduces average Mexican illegal migration by one third. Since mean enforcement is 2.19 million linewatch hours, the implied average enforcement elasticity of deterrence is -0.71 , negative but less than one (in absolute value). Thus, a 10 percent enforcement increase reduces migration by approximately 7 percent. The magnitude of the elasticity is similar across the different samples and specifications. ${ }^{34}$

\footnotetext{
${ }^{33}$ Note that the point estimates from columns 5 and 6 differ from the ones from columns 7 and 8 because they are estimated using slightly different samples. This is because when I transform the variables to account for autocorrelation (as in $Y_{t}=y_{t}-\hat{\rho} y_{t-1}$, where $y_{t}$ is the original variable and $\hat{\rho}$ is an estimated of the autocorrelation coefficient) I lose the first valid observation. In the time series estimates (columns 7 and 8) this means only dropping the first year, 1972. In the panel estimates I lose the first observed data point for each individual.

${ }^{34}$ Probit estimates of the partial effect of enforcement accounting for endogeneity through a control function approach have the same magnitude as the IV results reported in Table 2. I did not produce a table of the results because that the probit standard errors (estimated by block-bootstrap, where the block is the year) are biased because they do not account for the serial correlation in the residuals.
} 
Table 2: Effect of enforcement on illegal migration likelihood

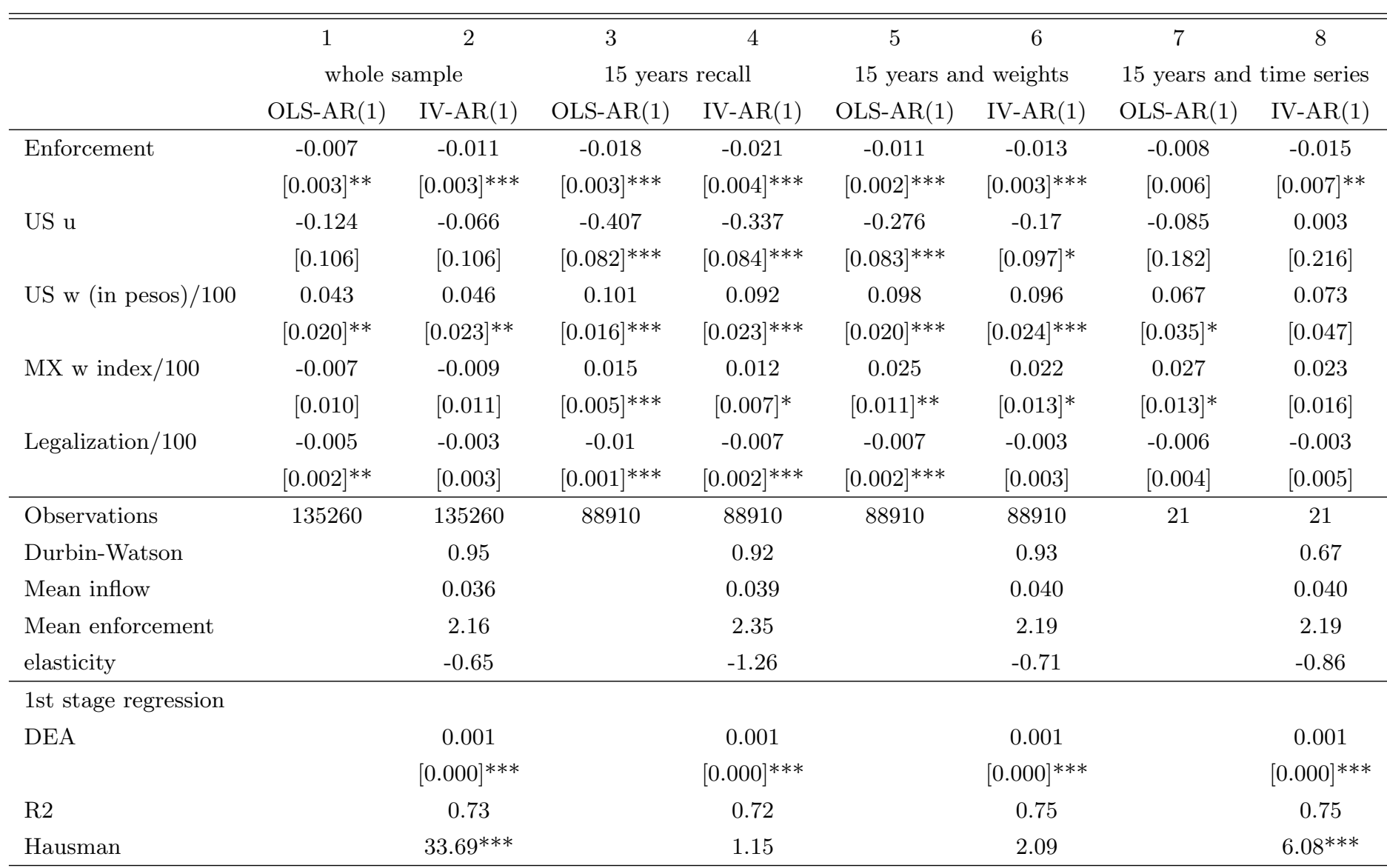

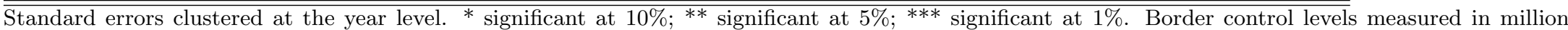
linewatch hours. The first-stage equation includes all the explanatory variables in the main regression, as well as the DEA budget. 
Looking at the other variables, higher returns from migration increase the incentives to leave Mexico, as shown by the negative effect on US unemployment and the positive effect of US wages (in pesos) on the likelihood of undertaking an illegal trip. Surprisingly, a higher Mexican wage index significantly increases the likelihood of becoming an illegal migrant. This result may suggest that during economic recessions it becomes harder to finance a trip, which may be quite costly for some potential migrants. Finally, higher legalizations are associated with a lower illegal migration likelihood, as the status of some migrants is changing from undocumented to legal.

Table 3 shows linear probability model (LPM) estimates of the marginal effect of enforcement on the likelihood of returning from an undocumented U.S. trip. Odd (even) columns provide OLS (IV) estimates of the parameter of interest. The first four columns use all available observations between 1972 and 1993, while the second four columns restrict the valid cases to a 15 year recall period. Columns 7 and 8 re-weight the observation to give each year equal weight. Again, the Durbin-Watson test provides evidence of positive serial correlation, hence I assume that the error term follows an $\mathrm{AR}(1)$ process. The instrument is positively correlated with enforcement in the first-stage equation and it is significant at the $1 \%$ level.

Column 2 presents IV estimates of this effect without cohort dummies. The estimated effect is not significantly different from zero. This coefficient is biased because it is correlated with the average level of the individual effect of current migrants, as explained in the previous section. If one expects enforcement to select "better" migrants, and if more highly skilled migrants are more likely to migrate back (perhaps because they can get across the border more easily in the future), then the enforcement coefficients in columns 1 and 2 are upward biased. Indeed, adding year-of-arrival dummies reduces the value of the border controls coefficient from 0.066 (column 2) and not statistically significant to -0.156 and significantly different from zero at $1 \%$ level (column 4). Given that the cohort dummy coefficients are positive and significantly larger for more recent arrivals ${ }^{35}$, I interpret this result as evidence that enforcement selects individuals with better skills by raising migration costs.

The estimated coefficients are in line with expectations, suggesting that tighter border patrol reduces the likelihood of returning from an illegal migration. The Hausman test provides evidence of the inconsistency of the OLS coefficients. A comparison of columns 7 and 8 shows that the enforcement coefficient from the OLS regressions is upward-biased: hence, shocks that increase the likelihood of returning from an illegal trip are positively correlated with enforcement levels.

\footnotetext{
${ }^{35}$ Results not shown but available upon request.
} 
Table 3: Effect of enforcement on the likelihood of returning from an illegal migration

\begin{tabular}{|c|c|c|c|c|c|c|c|c|}
\hline & 1 & 2 & 3 & 4 & 5 & 6 & 7 & 8 \\
\hline & \multicolumn{4}{|c|}{ whole sample } & \multicolumn{2}{|c|}{15 years recall } & \multicolumn{2}{|c|}{15 years and weights } \\
\hline & OLS-AR(1) & IV-AR(1) & OLS-AR(1) & IV-AR(1) & OLS-AR(1) & IV-AR(1) & OLS-AR(1) & IV-AR(1) \\
\hline \multirow[t]{2}{*}{ Enforcement } & -0.012 & 0.066 & -0.212 & -0.156 & -0.193 & -0.226 & -0.16 & -0.318 \\
\hline & {$[0.032]$} & {$[0.052]$} & {$[0.039]^{* * *}$} & {$[0.042]^{* * *}$} & {$[0.042]^{* * *}$} & {$[0.060]^{* * *}$} & {$[0.130]$} & {$[0.159]^{* *}$} \\
\hline \multirow[t]{2}{*}{ US u } & 1.533 & 1.353 & -0.274 & 0.457 & 0.276 & 0.9 & 0.637 & 1.839 \\
\hline & {$[0.894]$} & {$[1.093]$} & {$[1.065]$} & {$[1.100]$} & {$[1.370]$} & {$[1.351]$} & {$[3.419]$} & {$[3.368]$} \\
\hline \multirow[t]{2}{*}{ US w (in pesos) $/ 100$} & -0.556 & -0.701 & -0.101 & -0.208 & -0.124 & -0.108 & -0.575 & -0.275 \\
\hline & {$[0.221]^{* *}$} & {$[0.333]^{* *}$} & {$[0.234]$} & {$[0.248]$} & {$[0.257]$} & {$[0.296]$} & {$[0.978]$} & {$[1.017]$} \\
\hline \multirow[t]{2}{*}{ MX w index/100 } & -0.077 & -0.043 & 0.324 & 0.361 & 0.343 & 0.332 & -0.017 & -0.035 \\
\hline & {$[0.058]$} & {$[0.091]$} & {$[0.111]^{* * *}$} & {$[0.099]^{* * *}$} & {$[0.129]^{* *}$} & {$[0.113]^{* * *}$} & {$[0.350]$} & {$[0.356]$} \\
\hline \multirow[t]{2}{*}{ Legalization /100 } & -0.032 & -0.041 & -0.039 & -0.004 & -0.03 & -0.005 & -0.044 & -0.021 \\
\hline & {$[0.012]^{* *}$} & {$[0.026]$} & {$[0.034]$} & {$[0.024]$} & {$[0.029]$} & {$[0.028]$} & {$[0.120]$} & {$[0.128]$} \\
\hline Cohort & No & No & Yes & Yes & Yes & Yes & Yes & Yes \\
\hline Observations & 5925 & 5925 & 5925 & 5925 & 4200 & 4200 & 4200 & 4200 \\
\hline Durbin-Watson & & 0.50 & & 0.68 & & 0.68 & & 0.72 \\
\hline Mean outflow & & 0.45 & & 0.45 & & 0.47 & & 0.46 \\
\hline Mean enforcement & & 2.12 & & 2.12 & & 2.27 & & 2.26 \\
\hline Elasticity & & & & -0.73 & & -1.09 & & -1.56 \\
\hline \multicolumn{9}{|l|}{ 1st stage equation } \\
\hline \multirow[t]{2}{*}{ DEA } & & 0.001 & & 0.001 & & 0.001 & & 0.001 \\
\hline & & {$[0.000]^{* * *}$} & & {$[0.000]^{* * *}$} & & {$[0.000]^{* * *}$} & & {$[0.000]^{* * *}$} \\
\hline R2 & & 0.71 & & 0.84 & & 0.82 & & 0.86 \\
\hline Hausman & & $2.98^{*}$ & & $8.24^{* * *}$ & & 0.55 & & $2.88^{*}$ \\
\hline
\end{tabular}

$\overline{\bar{a}}$ : the values of the cohort dummy coefficients are significantly higher for more recent cohorts. Standard errors clustered at the year level. ${ }^{*}$ significant at $10 \%$; ${ }^{*}$ significant at $5 \%$; ${ }^{* *}$ significant at $1 \%$. Border control levels measured in million linewatch hours. The first-stage equation includes all the explanatory variables in the main regression, as well as the DEA budget. 
If there are common shocks to illegal migration inflow and outflow, this evidence is consistent with the idea that positive shocks to immigration, which induce the policy maker to increase border controls, also increase the current migrants' likelihood of returning to Mexico. For instance, consider the case of a currency devaluation in Mexico: this may provide additional incentives to become an illegal migrant, as the peso value of US salaries increases, but it also increases the peso purchasing power of savings (in dollars) of current undocumented migrants, inducing them to leave earlier. Thus, the shock may increase both the inflow and the outflow of undocumented Mexican migrants to the United States, as well as an endogenous tightening of border controls.

The estimated enforcement coefficient from column 8 implies that a one unit increase in border controls decreases the individual likelihood of leaving the United States by 31.8 percentage points. Since each year $46 \%$ of the population of U.S. resident illegal migrants leave the country to return to Mexico, such one-unit enforcement increase would decrease average returns by $69 \%$. The associated enforcement elasticity is -1.56 , negative and smaller than -1 , implying that a marginal increase in linewatch hours is associated with a more than proportional reduction in returns from illegal trips. Hence, it appears that current migrants' return decision are extremely sensitive to changes in migration costs. However, recall that the estimated partial effects may be upper bounds of the true effects: if some long-term illegal migrants are missing, the sampled individuals may be more sensitive to enforcement changes than the population of undocumented Mexican migrants.

\subsection{Robustness checks}

I test whether the results are sensitive to the chosen specification by slightly changing the set of conditioning variables: I replace the peso value of US wages by its dollar value, and add a variable measuring the intensity of Mexican currency devaluations. In this way, one can better understand how changes in push and pull factors affect the migration and return likelihoods. The sign, significance and magnitude of the enforcement partial effect do not change, as shown

in Tables 4 and 5. However, the values of the Hausman test are generally lower. Now US wages increase the likelihood of both becoming an undocumented migrant and returning from an illegal trip (although in this latter case the coefficient is seldom statistically significant). Peso devaluations increase the likelihood of leaving Mexico and decrease the one of leaving the United States. Now the Mexican wage index no longer increases the likelihood of migrating illegally, while it increases the probability of returning from an undocumented trip. The effect of legalization is unchanged. 
Table 4: Effect of enforcement on illegal migration likelihood - estimates from alternative set of regressors

\begin{tabular}{|c|c|c|c|c|c|c|c|c|}
\hline & 1 & 2 & 3 & 4 & 5 & 6 & 7 & 8 \\
\hline & \multicolumn{2}{|c|}{ whole sample } & \multicolumn{2}{|c|}{15 years recall } & \multicolumn{2}{|c|}{15 years and weights } & \multicolumn{2}{|c|}{15 years and time series } \\
\hline & OLS-AR(1) & $\operatorname{IV}-\operatorname{AR}(1)$ & OLS-AR(1) & $\operatorname{IV}-\mathrm{AR}(1)$ & OLS-AR(1) & $\operatorname{IV}-\mathrm{AR}(1)$ & OLS-AR(1) & $\operatorname{IV}-\mathrm{AR}(1)$ \\
\hline \multirow[t]{2}{*}{ Enforcement } & -0.004 & -0.02 & -0.01 & -0.025 & -0.015 & -0.016 & -0.003 & -0.028 \\
\hline & {$[0.004]$} & {$[0.009]^{* *}$} & {$[0.003]^{* * *}$} & {$[0.010]^{* *}$} & {$[0.002]^{* * *}$} & {$[0.003]^{* * *}$} & {$[0.007]$} & {$[0.024]$} \\
\hline \multirow[t]{2}{*}{ US u } & -0.09 & -0.241 & -0.26 & -0.462 & -0.293 & -0.257 & 0.028 & -0.188 \\
\hline & {$[0.110]$} & {$[0.173]$} & {$[0.057]^{* * *}$} & {$[0.203]^{* *}$} & {$[0.087]^{* * *}$} & {$[0.098]^{* * *}$} & {$[0.130]$} & {$[0.348]$} \\
\hline \multirow[t]{2}{*}{ US w (in dollars)/100 } & 0.005 & -0.007 & 0.014 & 0.003 & 0.014 & 0.01 & 0.01 & -0.008 \\
\hline & {$[0.004]$} & {$[0.008]$} & {$[0.004]^{* * *}$} & {$[0.009]$} & {$[0.003]^{* * *}$} & {$[0.004]^{* *}$} & {$[0.009]$} & {$[0.020]$} \\
\hline \multirow[t]{2}{*}{ MX w index/100 } & -0.018 & -0.011 & -0.013 & -0.007 & -0.006 & 0.003 & 0.013 & 0.023 \\
\hline & {$[0.011]$} & {$[0.015]$} & {$[0.007]^{*}$} & {$[0.016]$} & {$[0.010]$} & {$[0.013]$} & {$[0.019]$} & {$[0.043]$} \\
\hline \multirow[t]{2}{*}{ Legalizations/100 } & -0.003 & -0.004 & -0.006 & -0.007 & -0.007 & -0.004 & -0.003 & -0.004 \\
\hline & {$[0.002]$} & {$[0.003]$} & {$[0.001]^{* * *}$} & {$[0.002]^{* * *}$} & {$[0.001]^{* * *}$} & {$[0.002]$} & {$[0.004]$} & {$[0.007]$} \\
\hline \multirow[t]{2}{*}{ Peso devaluation } & 0.002 & 0.004 & 0.003 & 0.006 & 0.003 & 0.004 & 0 & 0.003 \\
\hline & {$[0.001]$} & {$[0.003]$} & {$[0.001]^{* * *}$} & {$[0.003]^{* *}$} & {$[0.001]^{* * *}$} & {$[0.002]^{* *}$} & {$[0.002]$} & {$[0.006]$} \\
\hline Observations & 135260 & 135260 & 88910 & 88910 & 88910 & 88910 & 21 & 21 \\
\hline Durbin-Watson & & 0.95 & & 0.92 & & 0.93 & & 0.67 \\
\hline Mean inflow & & 0.036 & & 0.039 & & 0.040 & & 0.040 \\
\hline Mean enforcement & & 2.16 & & 2.35 & & 2.19 & & 2.19 \\
\hline Elasticity & & -1.20 & & -1.50 & & -0.84 & & -1.53 \\
\hline \multicolumn{9}{|l|}{ 1st stage regression } \\
\hline \multirow[t]{2}{*}{ DEA } & & 0.0008 & & 0.0008 & & 0.0008 & & 0.0008 \\
\hline & & {$[0.0002]^{* * *}$} & & {$[0.0002]^{* * *}$} & & {$[0.0002]^{* * *}$} & & {$[0.0003]^{* *}$} \\
\hline $\mathrm{R} 2$ & & 0.82 & & 0.79 & & 0.84 & & 0.84 \\
\hline Hausman & & $3.87^{* *}$ & & 2.33 & & 0.37 & & 1.23 \\
\hline
\end{tabular}

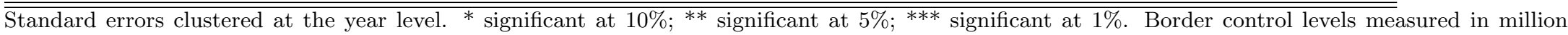
linewatch hours. The first-stage equation includes all the explanatory variables in the main regression, as well as the DEA budget. 
Table 5: Effect of enforcement on the likelihood of returning from an illegal migration - estimates from alternative set of regressors

\begin{tabular}{|c|c|c|c|c|c|c|c|c|}
\hline & 1 & 2 & 3 & 4 & 5 & 6 & 7 & 8 \\
\hline & \multicolumn{4}{|c|}{ whole sample } & \multicolumn{2}{|c|}{15 years recall } & \multicolumn{2}{|c|}{15 years and weights } \\
\hline & OLS-AR(1) & $\operatorname{IV}-\operatorname{AR}(1)$ & OLS-AR(1) & $\operatorname{IV}-\operatorname{AR}(1)$ & OLS-AR(1) & $\operatorname{IV}-\operatorname{AR}(1)$ & OLS-AR(1) & $\operatorname{IV}-\operatorname{AR}(1)$ \\
\hline \multirow[t]{2}{*}{ Enforcement } & -0.081 & 0.061 & -0.177 & -0.169 & -0.152 & -0.243 & -0.183 & -0.379 \\
\hline & {$[0.038]^{* *}$} & {$[0.098]$} & {$[0.040]^{* * *}$} & {$[0.054]^{* * *}$} & {$[0.039]^{* * *}$} & {$[0.092]^{* * *}$} & {$[0.160]$} & {$[0.192]^{* *}$} \\
\hline \multirow[t]{2}{*}{ US u } & 0.36 & 1.28 & 1.351 & 1.021 & 2.05 & 0.826 & -0.305 & 0.623 \\
\hline & {$[0.643]$} & {$[1.271]$} & {$[0.803]$} & {$[0.872]$} & {$[1.176]^{*}$} & {$[1.908]$} & {$[4.564]$} & {$[4.329]$} \\
\hline \multirow[t]{2}{*}{ US w (in dollars)/100 } & -12.923 & -6.621 & 9.145 & 6.578 & 6.379 & -0.461 & -8.283 & -9.248 \\
\hline & {$[3.839]^{* * *}$} & {$[5.700]$} & {$[3.187]^{* * *}$} & {$[3.975]^{*}$} & {$[4.314]$} & {$[5.689]$} & {$[7.168]$} & {$[7.346]$} \\
\hline \multirow[t]{2}{*}{ MX w index/100 } & 0.099 & 0.129 & 0.301 & 0.374 & 0.366 & 0.419 & 0.324 & 0.337 \\
\hline & {$[0.088]$} & {$[0.139]$} & {$[0.105]^{* * *}$} & {$[0.092]^{* * *}$} & {$[0.107]^{* * *}$} & {$[0.119]^{* * *}$} & {$[0.230]$} & {$[0.269]$} \\
\hline \multirow[t]{2}{*}{ Legalization/100 } & -0.064 & -0.05 & -0.018 & 0 & -0.01 & -0.008 & -0.049 & -0.021 \\
\hline & {$[0.011]^{* * *}$} & {$[0.020]^{* *}$} & {$[0.033]$} & {$[0.026]$} & {$[0.027]$} & {$[0.031]$} & {$[0.122]$} & {$[0.133]$} \\
\hline \multirow[t]{2}{*}{ Peso devaluation } & -0.017 & -0.029 & -0.026 & -0.021 & -0.031 & -0.017 & -0.003 & 0.006 \\
\hline & {$[0.011]$} & {$[0.025]$} & {$[0.009]^{* * *}$} & {$[0.012]^{*}$} & {$[0.012]^{* *}$} & {$[0.022]$} & {$[0.080]$} & {$[0.078]$} \\
\hline Cohort & No & No & Yes & Yes & Yes & Yes & Yes & Yes \\
\hline Observations & 5925 & 5925 & 5925 & 5925 & 4200 & 4200 & 4200 & 4200 \\
\hline Durbin-Watson & & 0.50 & & 0.70 & & 0.73 & & 0.73 \\
\hline Mean outflow & & 0.45 & & 0.45 & & 0.47 & & 0.46 \\
\hline Mean enforcement & & 2.12 & & 2.12 & & 2.27 & & 2.26 \\
\hline Elasticity & & & & -0.73 & & -1.09 & & -1.56 \\
\hline \multicolumn{9}{|l|}{ 1st stage equation } \\
\hline \multirow[t]{2}{*}{ DEA } & & 0.0009 & & 0.001 & & 0.0009 & & 0.0009 \\
\hline & & {$[0.0002]^{* * *}$} & & {$[0.000]^{* * *}$} & & {$[0.0002]^{* * *}$} & & {$[0.0002]^{* * *}$} \\
\hline $\mathrm{R} 2$ & & 0.80 & & 0.88 & & 0.85 & & 0.90 \\
\hline Hausman & & 2.49 & & 0.43 & & 1.21 & & $3.41^{*}$ \\
\hline
\end{tabular}

$\overline{\bar{a}}$ : the values of the cohort dummy coefficients are significantly higher for more recent cohorts. Standard errors clustered at the year level. $*$ significant

at $10 \%$; $*$ significant at $5 \%$; ** significant at $1 \%$. Border control levels measured in million linewatch hours. The first-stage equation includes all the explanatory variables in the main regression, as well as the DEA budget. 


\subsection{Interpretation and policy implications}

The values of the parameters of interest for the transitions from potential to current migrant status and vice versa cannot be directly compared, because they refer to two different populations (the set of all potential illegal migrants, in the first case, and the sub-set of actual migrants, in the second). I obtain an estimate of the marginal effect of border enforcement on the net flow of Mexican illegal migration in the following way. I compute the partial effect of a marginal increase in enforcement on both the inflow $(\bar{I})$ and the outflow $(\bar{O})$ of migration at mean values:

$$
\frac{\partial \bar{I}}{\partial b p}=\frac{\partial P\left(m_{i t}=1\right)}{\partial b p_{t}} \frac{\bar{I}}{\bar{P}}=\frac{\hat{\beta^{m}}}{\bar{P}} \bar{I}
$$

and

$$
\frac{\partial \bar{O}}{\partial b p}=\frac{\partial P\left(m_{i t}=1\right)}{\partial b p_{t}} \frac{\bar{O}}{\bar{P}}=\frac{\hat{\beta}^{r}}{\bar{P}} \bar{O}
$$

$\bar{P}$ is the observed migration proportion between 1972 and $1993 . \frac{\beta^{\hat{m}}}{\bar{P}}$ is the effect of a marginal enforcement increase on the migration likelihood in percentage, which, multiplied by $(\bar{I})$, tells how the marginal enforcement increase changes the average size of the inflow. The same logic applies to the estimate of the effect on the outflow. The marginal effect of enforcement on the net flow $(N F)$ is the difference between its partial effects on inflow and outflow

$$
\frac{\partial \overline{N F}}{\partial b p}=\frac{\partial \bar{I}}{\partial b p}-\frac{\partial \bar{O}}{\partial b p}
$$

I use the estimated partial effects of enforcement on immigration from Tables 2 and 4, columns 2, 4 and 6, and the partial effects on return from a migration from Tables 3 and 5, columns 4, 6 and 8. I consider alternatively the impact of hiring an additional patrolling agent and the effect of the average annual linewatch increase, which amounts to 77,500 hours. ${ }^{36}$ These results are presented in Table 6.

Consider the case of an employee working 40 hours per week, 50 weeks per year. This translates into 2,000 additional yearly linewatch hours. Such an increase implies a drop in inflow that ranges between 771 and 1621 migrants and a reduction in outflow that varies between 831 and 1966 individuals, with an overall change in the net flow ranging between a decrease of 503 and an increase of 995 migrants. Repeating the same exercise using the observed average annual enforcement increase suggests that 77,500 extra border patrolling hours cause an inflow reduction of 29,876 to 62,813 individuals, a drop in outflow of 32,201 to 76,182 illegal aliens, and a variation in the illegal migration net flow of $-19,491$ to 36,556 people.

\footnotetext{
${ }^{36}$ In this latter case I assume that the partial effect of enforcement is linear for a sufficiently large interval around the mean.
} 
Table 6: Estimates of enforcement marginal effect on illegal Mexican migration net flow, 19721993

\begin{tabular}{|c|c|c|c|c|c|c|c|c|c|}
\hline \multirow[b]{2}{*}{ Estimates from: } & \multicolumn{3}{|c|}{$\begin{array}{l}\text { Change in inflow } \\
\qquad(1)\end{array}$} & \multicolumn{3}{|c|}{$\begin{array}{l}\text { Change in outflow } \\
(2)\end{array}$} & \multicolumn{3}{|c|}{$\begin{array}{l}\text { Net change } \\
(3)=(1)-(2)\end{array}$} \\
\hline & $1 \mathrm{a}$ & $1 \mathrm{~b}$ & $1 c$ & $2 \mathrm{a}$ & $2 \mathrm{~b}$ & $2 \mathrm{c}$ & $3 a$ & $3 \mathrm{~b}$ & $3 \mathrm{c}$ \\
\hline & \multicolumn{9}{|c|}{ Hiring 1 extra patrolling agent } \\
\hline Tables 2 and 3 & -771 & -1361 & -822 & -831 & -1153 & -1661 & 60 & -208 & 830 \\
\hline \multirow[t]{2}{*}{ Tables 4 and 5} & -1404 & -1621 & -971 & -901 & -1228 & -1966 & -503 & -393 & 995 \\
\hline & \multicolumn{9}{|c|}{ Average annual enforcement growth } \\
\hline Tables 2 and 3 & -29876 & -52738 & -31852 & -32201 & -44678 & -64363 & 2325 & -8060 & 32162 \\
\hline Tables 4 and 5 & -54405 & -62813 & -37626 & -34913 & -47585 & -76182 & -19491 & -15228 & 36556 \\
\hline
\end{tabular}

Column (3) is the difference between columns (1) and (2). Columns a use the whole sample; columns b restrict the valid cases to maximum 15 years recall period; columns 3 use the same data from columns b but re-weight the observation to give each year the same weight.

It is worth stressing the multiple conclusions from the above exercise. First, gross undocumented migration greatly overestimates the size of net migration, as migrants are highly mobile and a large proportion of migrations are temporary. I estimated that, on average, nearly 1,265,000 Mexicans managed to cross the U.S. border each year between 1972 and 1993 . At the same time, migrant outflow is nearly as large, averaging $95 \%$ of annual inflow in the MMP71 sample.

Second, border patrol's deterrent effect on prospective undocumented migration is sizeable. Given the estimated values, and assuming linearity for a sufficiently large interval around the mean marginal effect, the average annual increase in border enforcement of 77,500 linewatch hours discourages approximately 30,000 to 63,000 individuals from crossing the border illegally (770 to 1,620 for one additional patrolling agent). However, current undocumented migrants' lower mobility largely offsets the deterrent effect: the average annual enforcement increase prevents some 32,000 to 76,000 illegal resident aliens from returning home (830 to 1,960 with one additional patrolling agent), since the tougher controls raise migration costs, and lengthen migrants' stay in the host country. The effect of border controls on returns from illegal trips may be overstated, since the available data may not include some permanent undocumented migrants. In any case, these results are interesting because they show how enforcement's effect on the level 
of illegal migration is only a small fraction of its impact on the undocumented inflow. Indeed, the estimates of the effect of border controls on migrant net flow are in some cases positive. This suggests that border enforcement may not be effective in reducing the level of illegal migration in the United States, or that it may do so at a very high cost, according to which sets of estimates one considers. Looking at the top right panel in Table 6 , and assuming a gross cost of $\$ 50,000$ for the employment of an extra patrolling agent, the associated net flow reduction of 208 to 503 migrants implies a marginal cost of 240 to 100 dollars per migrant. ${ }^{37} 38$ The cost is even higher if one considers that on average only 59 percent of work time is spent patrolling the border (GAO, 1996).

The outcome of this analysis raises interesting policy issues. Border controls do not seem to contribute to a sizeable reduction in the level of illegal resident aliens in the United States. Moreover, tight border enforcement seems to involuntarily create a more permanent population of illegal resident aliens. A more stable group of illegal migrants may have worse long-term effects on the stock of undocumented migration than a highly mobile one: the establishment of U.S.-based illegal migrant enclaves may decrease migration costs for prospective migrants (short-term migrants may lack both possibility and interest in helping others out). Moreover, participation in welfare programs might be a positive function of time spent in the United States. This additional indirect cost should be considered in any welfare analysis of the impact of border enforcement policies.

\section{Conclusions}

This paper contributes to the existing literature on Mexican illegal migration to the United States and its border enforcement. It points out that border enforcement influences both the inflow and outflow of illegal migration to the United States. In fact, more stringent border controls may not only deter potential undocumented migrants from entering the United States, but also lengthen the duration of current illegal trips, since they raise the cost of contemporaneous (and possibly future) migration. The resulting effect on illegal migration net flow is unclear. Subsequently, inferring the impact of the policy by observing how the inflow of undocumented migrants changes in response to tighter enforcement may be misleading.

The existing literature has not sufficiently acknowledged the need to look at both inflow and outflow of migrants, partly because of the scarce availability of direct information on undocumented migration. I overcome this difficulty by merging unpublished INS data on enforcement intensity along the Mexico-U.S. border with individual illegal migration information from the

\footnotetext{
${ }^{37}$ The cost would be infinite if one considered the positive estimates of the enforcement effect on the net flow.

${ }^{38}$ This computation ignores the additional benefits of the patrolling agent, such as apprehending drug smugglers.
} 
Mexican Migration Project (MMP71). I estimate the impact of border controls on the behavior of both prospective and current illegal migrants by modeling the likelihood of undertaking an undocumented migration and of returning from an illegal U.S. trip.

I estimate that the annual undocumented Mexican migrant inflow averages 1,265,000 between 1972 and 1993. Illegal migrants are very mobile: the annual average outflow amount to 1,202,000 in the same years. Both inflow and outflow are quite sensitive to changes in border controls: the enforcement elasticity is in several cases larger than one (in absolute value) for the likelihood of both undertaking and returning from an illegal migration. The effect of hiring an extra patrolling agent (i.e. 2000 extra linewatch hours per year) is a decrease in the undocumented inflow of 771 to 1621 individuals, but also a 831 to 1966 decrease in outflow. The overall impact on illegal migration net flow ranges from a decrease of of 503 to a 995 migrant increase.

These findings have interesting policy implications. First, they suggest that border enforcement may not be effective in curbing the level of illegal immigration in the United States. The estimated partial effects show that marginal enforcement increases cause at most a very small reduction in the migrant net flow, and that they actually may end up increasing it. A direct implication is that one may want to seek alternative policies to reduce the number of illegal resident aliens. Second, the findings show that enforcement's net effect on the level of illegal migration is only a small fraction - at most 35\% - of its impact on the inflow. Thus, if the enforcement level is chosen by looking at its impact on illegal migrant inflow only, it will likely result in too high levels of border controls. This may contribute to explain the disproportionate resource allocation to border versus interior enforcement. Finally, these results suggest that tight border policing may contribute to the creation of a more permanent unauthorized U.S. resident population - hence probably more costly in terms of welfare participation.

\section{Bibliography}

1. Borjas, G. (1987), "Self-selection and the earnings of immigrants", American Economic Review, 77(4), 531-53.

2. (1994), "The economics of immigration", Journal of Economic Literature, 32, 16671717.

3. - and Bratsberg, B. (1996), "Who Leaves? The Outmigration of the Foreign-Born", Review of Economics and Statistics, 78(1), 165-76.

4. — Freeman, R. B. and Lang, K. (1991), "Undocumented Mexican-Born Workers in the United States: how many, how permanent?", in Abowd, J.M. and Freeman R. B., eds., 
Immigration, trade and the labor market. Chicago, IL: University of Chicago Press, 1991, 77-100.

5. Blundell, R. W. and Smith, R. J. (1989), "Estimation in a class of simultaneous limited dependent variable models", Review of Economic Studies, 56(1), 37-57.

6. Bratsberg, B. (1995), "Legal versus illegal U.S. immigration and source country characteristics", Southern Economic Journal, 61(3), 715-27.

7. Chesher, A. and Lancaster, T. (1983), "The estimation of models of labor market behavior", Review of Economic Studies, 50, 609-624.

8. Colussi, A. (2004), "An estimable model of illegal Mexican immigration", unpublished $\mathrm{PhD}$ thesis, University of Pennsylvania.

9. Cornelius, W. (2001), "Death at the border: efficacy and unintended consequences of US immigration control policy", Population and Development Review, 27(4), 661-85.

10. Da Vanzo, J (1983), "Repeat migration in the United States: Who moves back and who moves on?", Review of Economics and Statistics, 65(4), 552-559.

11. Davila, A., Pagan, J.A. and Grau, M.V. (1999), "Immigration reform, the INS and the distribution of interior and border enforcement resources", Public Choice, 99(3-4), 327-45.

12. Davila, A., Pagan, J.A. and Soydemir, G. (2001), "The short-term and long-term deterrence effects of INS border and interior enforcement on undocumented immigration", Journal of Economic behavior and Organization, 49, 459-472.

13. Department of Justice. Immigration and Naturalization Service.

14. Donato, K.M., Durand, J. and Massey, D. (1992), "Stemming the tide? Assessing the deterrent effects of the IRCA", Demography, 29(2), 139-157.

15. Dustmann, C. (1997), "Return migration, uncertainty and precautionary savings", Journal of Development Economics, 52, 295-316.

16. (2003), "Return migration, wage differentials and the optimal migration duration", European Economic Review, 47(2), 353-67.

17. The Economist (2002), "A survey of migration", November 2 issue.

18. The Economist (2005), "Dangerous desert, breached border", pp.37-38, January 8 issue. 
19. Espenshade, T. (1994), "Does the threat of border apprehension deter US immigration?", Population and Development Review, 20(4), 871-92.

20. (1995), "Unauthorized immigration to the United States", Annual Review of Sociology, 21, 195-216.

21. (1995b), "Using INS border apprehension data to measure the flow of undocumented migrants crossing the U.S.-Mexico frontier", International Migration Review, $29(2), 545-565$.

22. Ethier, W.J. (1986), "Illegal immigration: the host-country problem", American Economic Review, 76(1), 56-71.

23. Hanson, G., Robertson, R. and Spilimbergo, A. (2002), "Does border enforcement protect US workers from illegal migration?", Review of Economics and Statistics, 84(1), 73-92.

24. — and Spilimbergo, A. (1999), "Illegal immigration, border enforcement and relative wages: evidence from apprehensions at the US-Mexico border", American Economic Review, 89(5), 1337-1357.

25. — and Spilimbergo, A. (2001), "Political economy, sectoral shocks and border enforcement", Canadian Journal of Economics, 34(3), 612-638.

26. Hill, J.K. (1987), "Immigrant Decisions Concerning Duration of Stay and Migratory Frequency", Journal of Development Economics, 25(1), 221-34.

27. Kossoudji, S. (1992), "Playing cat and mouse at the Mexican-American border", Demography, 29(2), 159-180.

28. Massey, D. (1987), "The Ethnosurvey in Theory and Practice", International Migration Review 21, 1498-1522.

29. Massey, D. and Espinosa, C. (1997), "What's driving Mexico-US migration? A theoretical, empirical and policy analysis", American Journal of Sociology, 102, 939-99.

30. Massey, D. and Singer, A. (1995), "New estimates of undocumented Mexican migration and the probability of apprehension", Demography, 32(2), 203-13.

31. Massey, D. and Zenteno, R. (1999), "A validation of the ethnosurveys: The case of MexicoU.S. migration", International Migration Review, 33, 766-793.

32. Meghir, C. and Whitehouse, E. (1997), "Labor market transitions and retirement of men in the UK", Journal of Econometrics, 79, 327-354. 
33. Mexican Migration Project (2001), www.pop.upenn.edu/mexmig.

34. Munshi, K. (2003), "Networks in the modern economy: Mexican migrants in the U.S. labor market", Quarterly Journal of Economics, 549-99.

35. Schick, F and Schick, R. editors (1991), Statistical Handbook on U.S. Hispanics, Phoenix, Arizona: Oryx Press.

36. Smith, R. J. and Blundell, R. W. (1986), "An exogeneity test for a simultaneous equation tobit model with an application to labor supply", Econometrica, 54(3), 679-86.

37. Stark, O., Helmenstein, C. and Yegorov, Y. (1997), "Migrants' savings, purchasing power parity, and optimal migration duration", International Tax and Public Finance, 4(3), 30724.

38. United States General Accounting Office (1991), "Border Patrol. Southwest border enforcement affected by mission expansion and budget", GAO/GGD91-72BR.

39. United States General Accounting Office (1996), "Border Patrol. Staffing and enforcement activities", GAO/GGD96-65.

40. Warren, R. and Passel, J. (1987), "A count of the uncountable: estimates of undocumented aliens counted in the 1980 United States Census", Demography, 24(3), 375-393

41. Warren, R. INS Statistical Yearbooks, Immigration and Naturalization Service (now in the Department of Homeland Security).

42. Warren, R. (1994), Estimates of the unauthorized immigrant population currently residing in the United States, by country of origin and state of residence: October 1992. Washington, DC: Statistical Division, Immigration and Naturalization Service. 